\title{
MEASUREMENTS ON THE THERMAL DILATATION OF GLASS AT HIGH TEMPERATURES
}

\author{
By C. G. Peters and C. H. Cragoe
}

CONTENTS

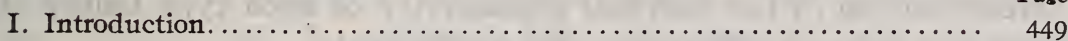

I. Micrometric method .............................. $45^{\circ}$

2. Interference method $\ldots \ldots \ldots \ldots \ldots \ldots \ldots \ldots \ldots \ldots \ldots \ldots, 45^{2}$

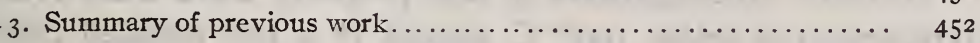

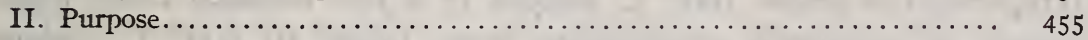

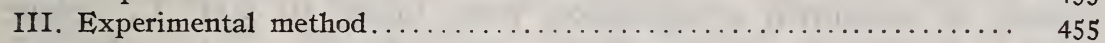

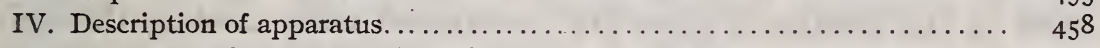

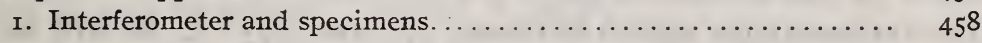

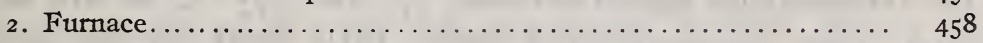

V. Experimental procedure................................ 460

I. Optical adjustments........................... 460

2. Temperature regulation and observations................ $46 \mathrm{I}$

VI. Experimental results................................. 462

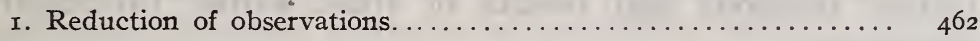

2. Values for mean coefficient of expansion................ 462

3. Chemical composition.................................... $46_{3}$

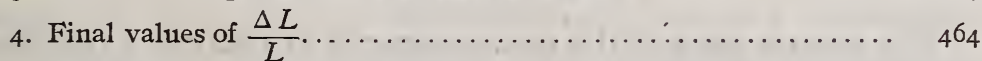

5. Dimensional change above the critical temperature........ 476

6. Comparisons of dimensional changes and heat absorption....... 483

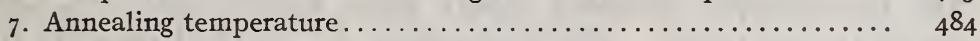

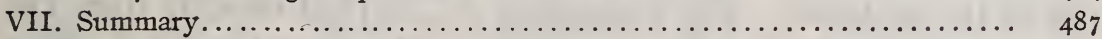

\section{INTRODUCTION}

The dilatation or dimensional change of glass with variation in temperature affects its thermal resistance, optical properties, and dimensional permanency, and is often the direct cause of difficulties encountered in working glass. The cracking or breaking of articles made of glass when subjected to sudden temperature changes is familiar to everyone. When glass is cooled rather quickly from the molten state, strains are set up by the unequal expansions or contractions of the inner mass and outer layer. If these strains are present in the optical elements of an instrument they may cause, for example, variation in the refractive index 
throughout a prism, changes in the curvature of a lens, distortion of the plane surface of a plate, or, in some cases, shattering of the glass. Proper annealing, in order to remove the strains, is therefore of prime importance.

But no annealing procedure will prevent sealed junctions of glasses having different expansivities from cracking, or seals between metals and glass, as in the case of incandescent lamps, from presenting serious difficulties unless the expansivities are nearly the same. The thermal expansivity of materials known as glass depends on their chemical compositions, which may be extremely complicated and widely different. This necessitates a determination of the thermal expansivity of each type before the glass can be used effectively and intelligently.

Previous investigations of this property have been confined to temperatures below $100^{\circ} \mathrm{C}$, except in a few isolated cases when glasses of unknown composition were taken to $500^{\circ} \mathrm{C}$. Since most of the strains in glass are introduced while cooling through the temperature region between 575 and $475^{\circ} \mathrm{C}$, as will be shown later, these measurements throw little light on the subject of annealing. They do, however, furnish the rate of expansion below the annealing region. Hence, a brief review of the experimental methods and results of these earlier investigations is appropriate.

\section{MICROMETRIC METHOD}

The greater part of the measurements of thermal expansion have been made, by direct observation of the elongation, with micrometer microscopes focused upon lines ruled near the ends of a rod of the material. The elongation $\Delta L$ is read directly from the micrometer head, the mean coefficient of expansion for a given temperature interval $\Delta t$ being given by

$$
C=\frac{\Delta L}{L \Delta t}
$$

where $L$ is the original length of the specimen. This method was used by Callender ${ }^{1}$ for determining the thermal expansion of hard glass (from a gas thermometer) in the temperature interval 17 to $494^{\circ} \mathrm{C}$. A tube $63 \mathrm{~cm}$ by $5 \mathrm{~mm}$, which had been drawn doẉn to a fine capillary at each end, was heated in an iron-tube gas furnace and then allowed to cool. The measurements were made while the specimen was cooling, because a permanent contraction due to change in structure of the glass took place at the higher 
temperature. This permanent contraction amounted to 0.052 per cent of the length of the tube on the first heating and 0.026 per cent on the second. Later in their work on the boiling point of sulphur, Callender and Griffiths ${ }^{2}$ determined the thermal expansion of a specimen of glass tubing. A permanent contraction of 0.056 per cent of the sample's length was found after the first of five heatings to $400^{\circ} \mathrm{C}$. The amount of the contraction decreased upon successive heatings.

This same effect was observed by Holborn and Grüneisen ${ }^{3}$ in their work on the thermal expansion of Jena $59^{\text {mI }}$ glass. A rod ( 5.7 by $435.8 \mathrm{~mm}$ ), when held (in a horizontal electric furnace) at $55^{\circ} \mathrm{C}$ for five hours, shortened $0.79 \mathrm{~mm}$. With the temperature held at $500^{\circ} \mathrm{C}$, readings taken in one-half hour intervals revealed successive contractions of $0.084,0.038,0.036$, and $0.018 \mathrm{~mm}$.

Thiesen, Scheel, and Sell, ${ }^{4}$ and Henning, ${ }^{5}$ used the micrometric method for the determination of the thermal expansion of thermometer glasses between - I 9 I to $+100^{\circ} \mathrm{C}$.

M. So ${ }^{6}$ investigated the thermal expansion of glass rods, I by $300 \mathrm{~mm}$, which were suspended within a vertical, electrically heated, iron-tube furnace. A $25 \mathrm{~g}$ weight was fastened to the lower end of the rod, and the expansion was measured with micrometer microscopes fastened to the same iron pillar which supported the specimen. The expansion of this pillar, which might have introduced an error in the determination, was not considered. With this apparatus sixteen different kinds of glass were examined, the data and curves for four of which are presented in his paper. These curves show a nearly linear expansion from room temperature to $400^{\circ} \mathrm{C}$. With the unannealed glass, a considerable contraction, not shown by the annealed glass, occurred during the next $50^{\circ}$ rise in temperature. Beyond $45^{\circ}$ a rapid elongation took place, due perhaps to a stretching of the plastic glass by the $25 \mathrm{~g}$ weight.

\footnotetext{
2 Callender and Griffiths, Phil. Trans. Roy. Soc., 182, p. I23; r89r.

3 Holborn and Crüneisen, Ann. d. Phys., 311, p. rз6; r9or.

4 Thiesen, Scheel, and Sell, Zs. f. Instrk., 16, p. 49; I896.

6 Henning, Ann. d. Phys., 22, p. 63r; 1907.

${ }^{6}$ M. So, Tokyo Math. Phys. Soc. Proc., 9, p. $425 ;$ Igr 7 -I8.
} 


\section{INTERFERENCE METHOD}

With the interference method originated by Fizeau ${ }^{7}$ and later developed by Pulfrich, ${ }^{8}$ the change in length of a ring or tripod of the material which acts as a separator for the two interferometer plates is determined from the shift of the straight interference fringes past a reference mark. This method has been emplnyed by many observers for determining the expansion of small samples of various substances over a wide temperature range, but the measurements on glass have been confined to the lower temperature region. Reimerdes ${ }^{9}$ reached a temperature of $220^{\circ}$ in his work on three samples of Jena glass. Pulfrich, Winklemann, and Weidmann ${ }^{10}$ determined the thermal expansion of a number of glasses of known chemical composition over the temperature range 5 to $95^{\circ} \mathrm{C}$. This work was part of an extensive and thorough investigation of optical glass carried out at the factory of Schott \& Genossen, Jena.

Dorsey $^{11}$ measured the expansion coefficient of glass tubing of unknown chemical composition between +20 and $-170^{\circ} \mathrm{C}$.

\section{SUMMARY OF PREVIOUS WORK}

The results of this previous work on the thermal expansion of glass are summarized in Table $\mathrm{I}$. All determinations for temperatures above $100^{\circ} \mathrm{C}$ have been recorded, although those for glasses of unknown composition are of little value. The measurements made in the temperature interval o to $100^{\circ} \mathrm{C}$, on different types of glass of known composition, were collected from Hovestadt. In a few cases measurements made during the present investigation, are, for comparison purposes, also included in this table.

\footnotetext{
${ }^{7}$ Fizeau, Ann. d. Phys., 128, p. 56.; 1866.

${ }^{10}$ Hovestadt, Jena glass, p. 234.

8 Pulfrich, Zs. f. Instrk., 13, p. $365 ; 1893$.

II Dorsey, Phys. Rev., 25, p. 88; 1907.

9 Reimerdes, Dissertation, Jena; 1896.
} 


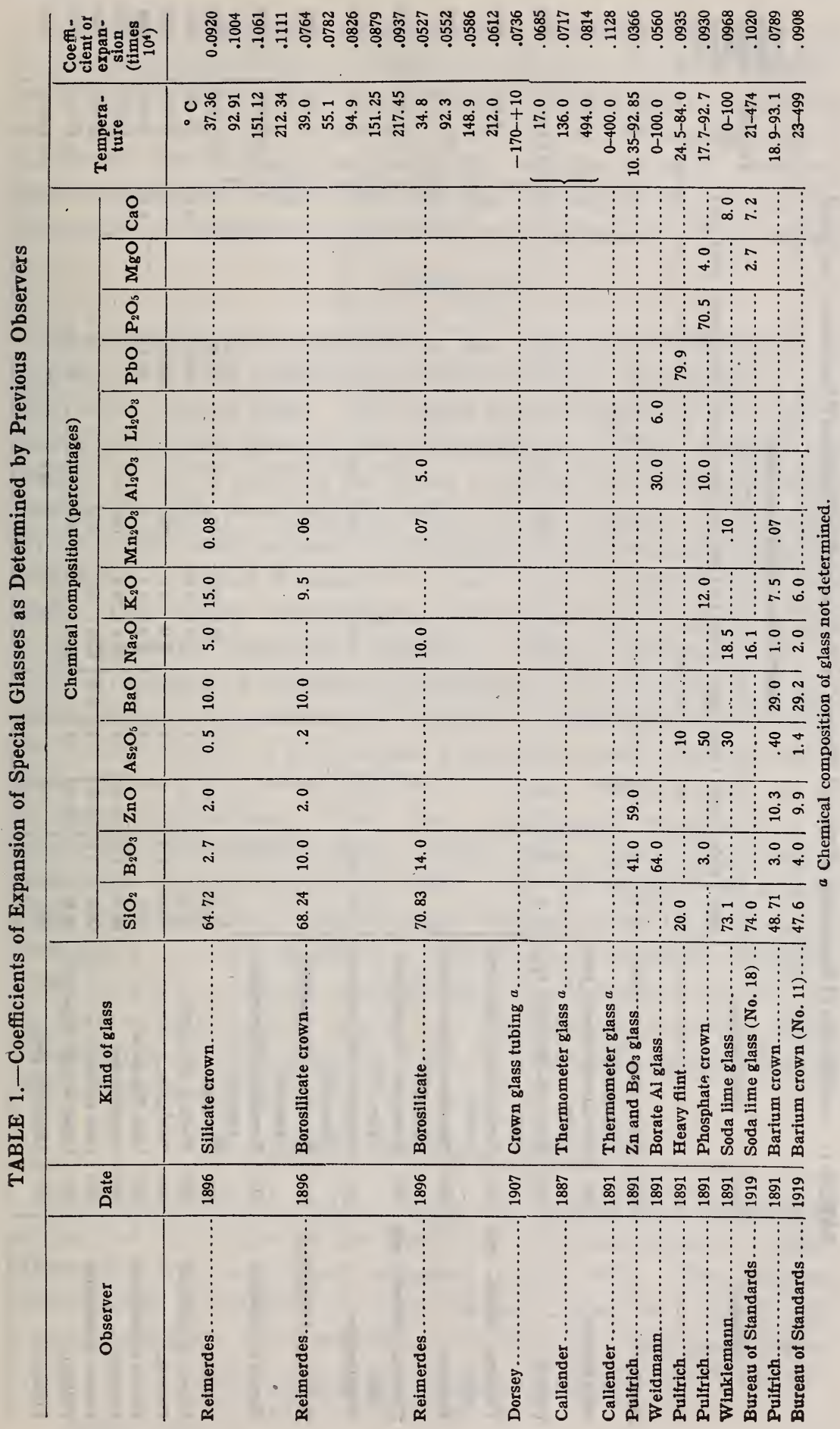




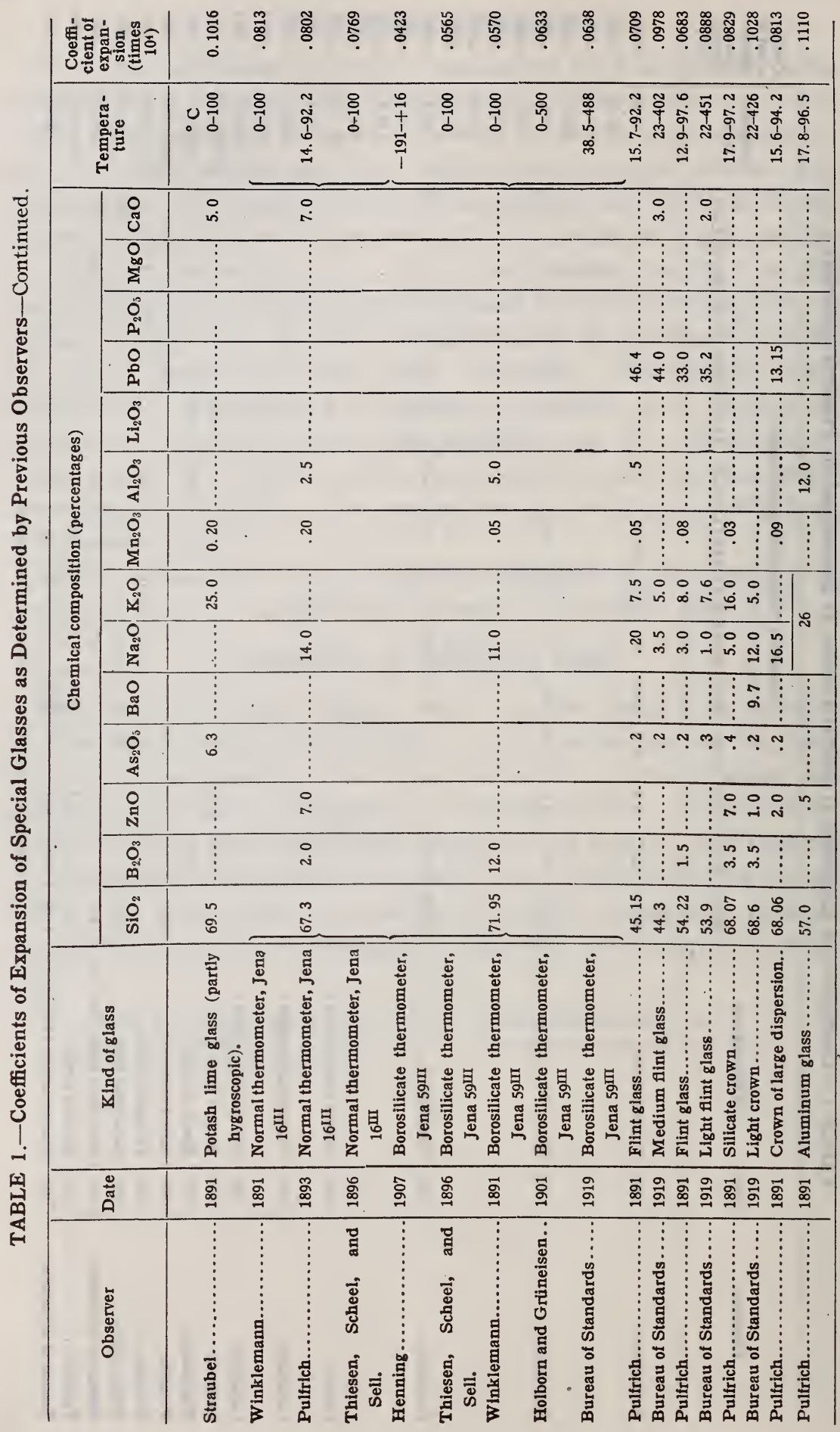


With few exceptions these previous investigations show the expansion of glass to be quite regular between - I9I and $+500^{\circ} \mathrm{C}$, so that the various observers were able to represent the coefficient of expansion by the equation $C=a+b t$. In the experiments of Callender and Holborn, however, the samples showed considerable contraction when held at $500^{\circ} \mathrm{C}$, and $\mathrm{M}$. So found the expansion of unannealed glass to be quite irregular in that region.

\section{PURPOSE}

The investigation described in this paper was undertaken in January, I918, in connection with the Bureau of Standards production of optical glass. The object was to determine the dimensional changes of glass in the annealing and higher temperature region, to find if possible the cause of the strain introduced while cooling through the annealing range, and to bring out any relation which might exist between the dilatation and the heat absorption found by Tool and Valasek ${ }^{12}$ in their study of the annealing of glass. Our earlier observations, made on several types of optical glass (presented before the American Physical Society ${ }^{13}$ and the Optical Society of America, December, 1918), showed a nearly linear expansion for about the first five hundred degrees. During the next one hundred degrees rise a rapid increase in the expansion occurred, and this was followed at higher temperatures by an apparent contraction. Since then, additional experiments on specimens from different kinds of plate glass, chemical glassware, and glass tubing have been made. At the request of several glass manufacturers, some of their products have also been investigated. To the apparent contraction at the higher temperatures, which is evidently a spheroiding due to surface tension, we have given considerable study. A complete report of the entire investigation, to date, together with the chemical analyses of most of the glasses, is presented in this paper.

\section{EXPERIMENTAL METHOD}

The Fizeau-Pulfrich method, which has been in use for a number of years at the Bureau of Standards for the measurement of small dilatations, was particularly adapted to this work. The extreme sensitiveness of the interferometer makes it possible to work with a small specimen of the material. Furthermore, the small size of

12 Tool and Valasek, B. S. Scientific Papers, No. 358.

13 Peters, Phys. Rev., p. 147; Feb., 1919.

$183538^{\circ}-20-2$ 
this apparatus simplifies the problems of uniform heating and temperature control. The experimental method was as follows: The straight fringes produced by rays of light reflected from the two interferometer plates were observed with a Pulfrich ${ }^{14}$ apparatus. Any elongation $\Delta L$ in the length $L$ of the specimen which forms a separator for the plates causes a corresponding movement of the interference fringes past a reference mark.

In passing from condition $\mathrm{I}$, with the plates at a distance apart equal to $L$, to condition 2 , with the plates at a distance equal to $L+\Delta L$, a band passes the reference mark each time the total number of wave lengths in the path (double distance) changes by one. This holds both when varying the wave length and varying the distance between the plates. The number of recorded passages $\Delta N$ is then obviously equal to the difference in the number of wave lengths in the double distance under the two conditions. If $\lambda_{\nu}$ represents the wave length when a vacuum exists between the plates, then

$$
\Delta N=2 \frac{L+\Delta L}{\lambda_{\nu}}-2 \frac{L}{\lambda_{\nu}}
$$

and the mean coefficient of expansion

$$
C=\frac{\lambda_{\nu} \Delta N}{2 L \Delta t}
$$

Maintaining a vacuum at high temperatures presents serious difficulty, so in the present work the interferometer was operated in air at atmospheric pressure. The number of passages is then represented by

$$
\begin{aligned}
\Delta N & =2 \frac{(L+\Delta L)}{\lambda_{2}}-\frac{2 L}{\lambda_{1}}, \\
& =2\left[\frac{(L+\Delta L)}{\lambda_{\nu}} \cdot \frac{\lambda_{\nu}}{\lambda_{2}}-\frac{L}{\lambda_{\nu}} \cdot \frac{\lambda_{\nu}}{\lambda_{1}}\right], \\
& =2\left[\frac{L+\Delta L}{\lambda_{\nu}} \cdot n_{2}-\frac{L}{\lambda_{\nu}} \cdot n_{1}\right]
\end{aligned}
$$

where $\lambda_{1}$ is the wave length and $\frac{\lambda_{v}}{\lambda_{1}}=n_{1}$ the refractive index of air under condition I; and likewise, $\lambda_{2}$, the wave length, and $\frac{\lambda_{\nu}}{\lambda_{2}}=n_{2}$, the refractive index of air under condition 2. Since in a gas the excess of its refractive index over unity is proportional to the den- 
sity, and the latter directly proportional to the pressure $P$ and inversely proportional to the absolute temperature $T$,

$$
\frac{n_{\mathrm{t}, \mathrm{p}}-\mathrm{I}}{n_{\mathrm{o}}-\mathrm{I}}=\frac{273}{T} \cdot \frac{P}{76 \mathrm{o}}
$$

$n_{\mathrm{o}}$ being the refractive index at $0^{\circ} \mathrm{C}, 760 \mathrm{~mm}$. From this relation,

likewise,

$$
n_{1}=\mathrm{I}+\left(n_{\mathrm{o}}-\mathrm{I}\right) \frac{273}{760} \cdot \frac{P_{1}}{T_{1}}
$$

$$
n_{2}=\mathrm{I}+\left(n_{\mathrm{o}}-\mathrm{I}\right) \frac{273}{760} \cdot \frac{P_{2}}{T_{2}}
$$

Substituting these values in (3) and collecting, we obtain the increase in length or the dilatation.

$$
\Delta L=\frac{\frac{\lambda_{\nu} \Delta N}{2}+L\left(n_{\mathrm{o}}-\mathrm{I}\right) \frac{273}{760}\left(\frac{P_{1}}{T_{1}}-\frac{P_{2}}{T_{2}}\right)}{\mathrm{I}+\left(n_{\mathrm{o}}-\mathrm{I}\right) \frac{273 P_{2}}{760 T_{2}}}
$$

Making the denominator of the right-hand member of this equation equal to unity introduced an error less than 0.03 per cent in our results, since $n_{0}-\mathrm{I}=0.0003$, and $T_{2}$ was always greater than 273. We may, then write

$$
\Delta L=\frac{\lambda_{\nu} \Delta N}{2}+L\left(n_{0}-\mathrm{I}\right) \frac{273}{760}\left(\frac{P_{1}}{T_{1}}-\frac{P_{2}}{T_{2}}\right) .
$$

For the yellow radiation of helium, which was used to illuminate the interferometer, we used $\lambda_{\nu}=5877 \times 10^{-8} \mathrm{~cm}$ and for $\left(n_{0}-I\right),{ }^{15}$ 0.0002918 . To obtain the dilatation in microns per centimeter, (4) must be divided by $L \times 10^{-4}$ when $L$ is measured in centimeters. To obtain the mean coefficient, (4) must be divided by $L \Delta t$, where $\Delta t$ is the temperature interval $\left(T_{2}-T_{1}\right)$. This gives,

$$
C=\frac{\Delta L}{L \Delta t}=\frac{\lambda_{\nu} \Delta N}{2 L \Delta t}+\frac{273}{760} \frac{\left(n_{\mathrm{o}}-\mathrm{I}^{\prime}\right)}{\Delta t}\left(\frac{P_{1}}{T_{1}}-\frac{P_{2}}{T_{2}}\right)
$$




\section{DESCRIPTION OF APPARATUS}

\section{INTERFEROMETER AND SPECIMENS}

The two plates, $A$ and $B$, of the interferometer represented in Fig. I, were made of fused quartz, which can be heated to $1000^{\circ} \mathrm{C}$ without serious injury to the surfaces. The upper surface of the base plate $B$ was polished true plane, while the lower surface was left in the ground condition to avoid regular reflection from it. Both surfaces of $A$ were polished true plane and adjusted to make an angle of $2 \mathrm{O}^{\prime \prime}$ with each other, so that light reflected from the upper surface could be diaphragmed out of the viewing apparatus. The circle $E$, I $\mathrm{mm}$ in diameter, ruled on

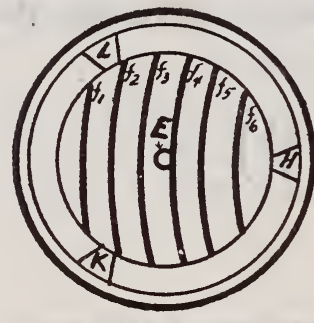
the lower surface of $A$, constituted the reference mark. The separator $S$, the test piece, consisted of a section of tubing about I $\mathrm{cm}$ long and $3 \mathrm{~cm}$ in diameter, or a ring of these dimensions cut from a block of glass, or a tripod made from three sections of glass rod. The end surfaces of the rings were ground until parallel to one another; then part of the material was cut away, leaving three triangular areas as bearing points at

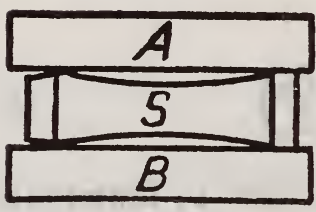

Fig. I.-Interferometer each end. These bearing points were adjusted to give about eight interference bands across the plates, which meant that the separation of the plates at $H$ was about $2 \mu$ greater than at $K$ and $L$. A uniform expansion of the ring caused the fringe system to move toward the left, while any unequal expansion at the three points $H, K$, and $L$, produced also a rotation and change in width of the fringes.

\section{FURNACE}

A sectional view of the electric furnace containing the interferometer is given in Fig. 2. A porcelain tube $F, 5 \mathrm{~cm}$ in diameter and $30 \mathrm{~cm}$ long, wound spirally with a heating coil $K$, is mounted vertically in a sheet-iron jacket and surrounded with insulating material. A smaller porcelain tube $E$, which extends from the base to about $3 \mathrm{~cm}$ from the center of the furnace, supports the porcelain disc $D$, the intervening space below this disc being filled with an insulating material. A porcelain cup $C$ with a cover $H$ 
acts as a container for the interferometer $A S B$ and can be lowered into the furnace by a platinum wire until it rests on the disc $D$. The upper end of the furnace is closed by another porcelain tube containing two fused quartz windows $W_{1}$ and $W_{2}$. A sheet of asbestos board with a glass window $W_{3}$ covers the entire furnace.

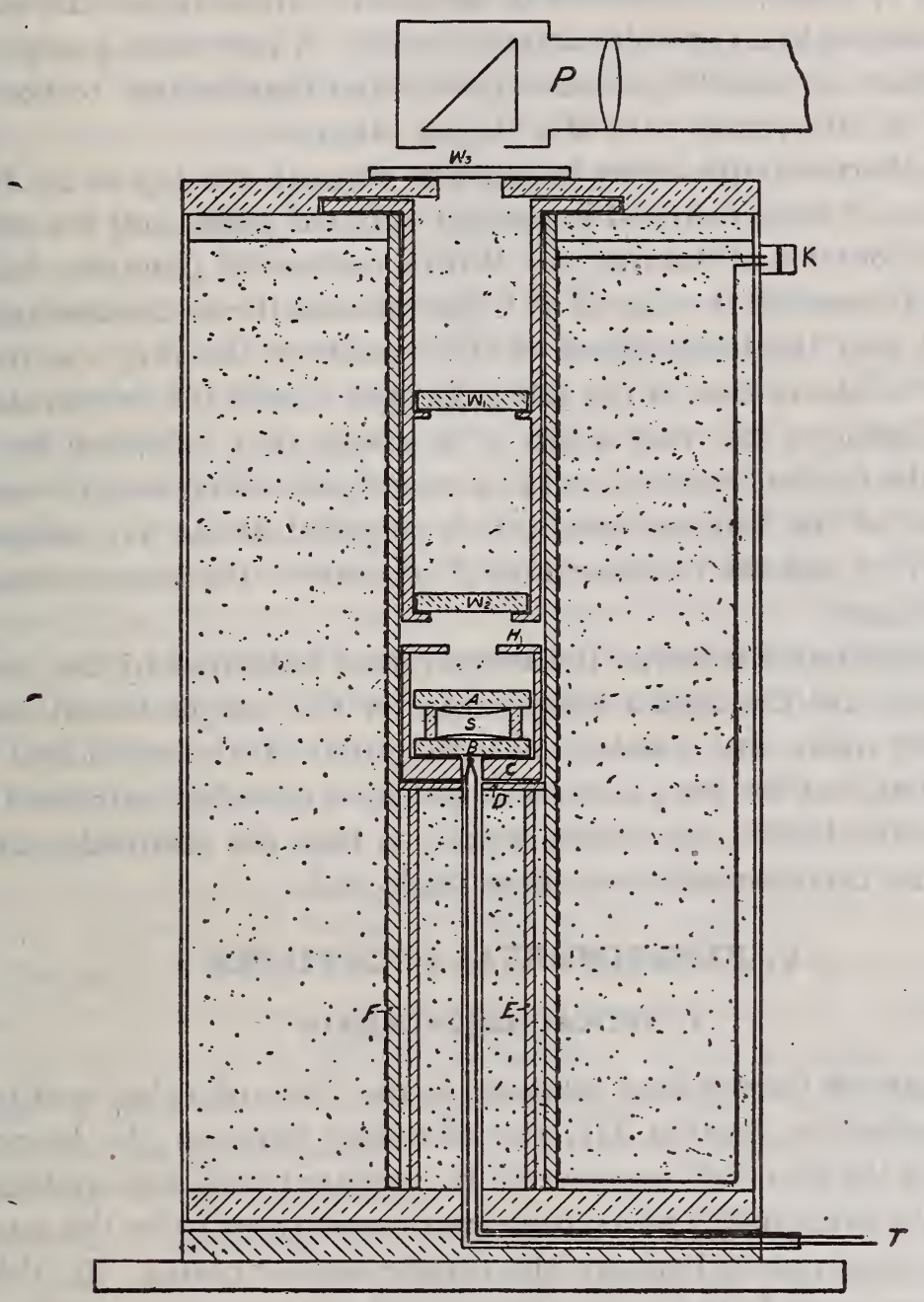

Fig. 2.- Electric furnace

The Pulfrich apparatus, which contains a helium lamp for illuminating the interferometer and the optical arrangement necessary for measuring the displacement of the fringes, is represented by $P$.

A small double-bore porcelain tube containing a calibrated $\mathrm{Pt}$ $\mathrm{Pt}-\mathrm{Rh}$ thermocouple $T$ passes through the base of the furnace, 
the disc $D$, and the bottom of the container $C$, the thermocouple junction being adjusted so that it nearly touches the lower interferometer plate $B$. By this arrangement the interferometer can be removed from the furnace without interfering with the adjustment of the thermocouple. The heating coil $K$, which has a resistance of $\mathrm{I} 7 \mathrm{ohms}$, is connected in series with an ammeter and suitable rheostat to a I Io-volt battery circuit. A current of 4 amperes is sufficient to heat the furnace from room temperature to 600 or $700^{\circ} \mathrm{C}$ at an average rate of $4^{\circ} \mathrm{C}$ per minute.

Two thermocouples were brought in through the top of the furnace, one of them fastened in contact with the inside and the other with the outside of the ring $S$. With a current of 4 amperes heating the furnace at the rate of $4^{\circ} \mathrm{C}$ per minute, these thermocouples showed that the temperature of the outside of the ring was from 8 to $10^{\circ} \mathrm{C}$ above that of the thermocouple $T$, and the temperature of the inside of the ring about $3^{\circ} \mathrm{C}$ above that indicated by $T$. When the current was reduced to a magnitude which held the temperature of the furnace constant, it required about five minutes for the ring and the thermocouple $T$ to come to the same constant temperature.

This difference between the temperature indicated by the thermocouple and the actual temperature of the sample would have an effect upon any absolute determination of the coefficient of expansion, but we were concerned chiefly with what happened to glass in the high-temperature region, so that the relatively small lag of the thermocouple was often neglected.

\section{EXPERIMENTAL PROCEDURE}

\section{OPTICAL ADJUSTMENTS}

The sample having been prepared in the shape of a ring or tripod as described in Section III, the distances between the bearing points of the two ends were carefully measured with a micrometer. When the micrometer measurements showed these to be the same, the ring was placed between the interferometer plates. If, then, the fringes were found to be distinct and of the desired width, no further adjustments were necessary, but if they were too narrow a slight change in the distance between one set of bearing points brought them to the required width.

With these adjustments made, the interferometer was placed in the cup $C$ and carefully lowered into the furnace. The Pulfrich apparatus was then. brought into adjustment, and the fractional 
part of the fringe width represented by the distance from the reference mark to the first fringe to the left was accurately measured. In Fig. I this fraction would be about 0.7.

\section{TEMPERATURE REGULATION AND OBSERVATIONS}

After being lowered into place, about 20 minutes was allowed for the sample and container to assume the temperature of the furnace. In some cases, before proceeding with the observations, the furnace containing the interferometer was heated to roo or $200^{\circ} \mathrm{C}$ and allowed to cool overnight, so that air films which might separate the plates from the bearing points would thus be driven off or at least reduced. The current from the I Io-volt battery was then turned on and regulated to about 4 amperes. The temperature of the furnace, which rose at the rate of $4^{\circ}$ per minute, was carried to as high a temperature as the nature of the sample would permit. The expansion of the sample due to this heating caused the interference fringes to move across the field, the number that passed the reference mark being counted. As every fifth fringe passed the mark both the time and the reading of the thermocouple as shown by the potentiometer were recorded. With all the glasses investigated, the expansion up to a certain temperature (usually about $500^{\circ} \mathrm{C}$ ) was quite uniform and regular; but at this critical region, which varied with different glasses, the movement of the fringes became more rapid, denoting an increase in the rate of expansion of the glass. With a further rise in the temperature, the fringes continued to shift at the increased rate, then slowed down, stopped, and began to drift in the opposite direction, incicating a shortening of the sample. The heating when continued for 20 to $30^{\circ}$ beyond this point was accompanied by a rapid increase in the contraction of the sample. At this higher temperature the glass was undoubtedly in a plastic condition, in most cases fusing to the quartz plates. The current was reduced at this point and the sample allowed to cool. When the temperature had dropped to the region where the rapid expansion had taken place, the glass hardened, broke away from the plates, thus throwing the interferometer out of adjustment and rendering further observations impossible. Pieces of quartz were often torn from the surfaces of the plates and the bearing points broken from the ring when the fracture took place.

In a few cases, observations were made at intervals of 50 to $100^{\circ}$ with the temperature held constant long enough to eliminate the lag in the temperature of the thermocouple behind that of the 
ring. The results thus obtained were not sufficiently different from those observed under steady heating conditions to warrant losing the additional time required to follow this procedure.

\section{EXPERIMENTAL RESULTS}

\section{REDUCTION OF OBSERVATIONS}

The dilatation or change in length of the sample in microns per centimeter, $\frac{\Delta L}{L}$, was obtained from equation (4).

$$
\frac{\Delta L}{L}=\frac{\lambda_{\nu} \Delta N}{2 L}+\frac{273}{760}\left(n_{\mathrm{o}}-\mathrm{I}\right)\left(\frac{P_{1}}{T_{1}}-\frac{P_{2}}{T_{2}}\right)
$$

The value of the first term was obtained by multiplying the number of fringes which passed the reference mark by the wave length in vacuum and dividing by twice the length of the sample. The values for $\frac{273\left(n_{0}-1\right) P}{760 T}$ with a I $\mathrm{cm}$ separation of the plates were computed for temperatures from o to $1000^{\circ} \mathrm{C}$ and pressures from 730 to $760 \mathrm{~mm}$, and these plotted against the temperature. The value of the last term for any temperature interval was then read directly from the curve. No correction needed to be made for the small variation of the atmospheric pressure during the experiment.

The mean coefficient of thermal expansion over the temperature interval $\Delta t$ was obtained from equation (5).

\section{VALUES FOR MEAN COEFFICIENT OF EXPANSION}

The mean coefficients of linear expansion of the different glasses as computed from equation (5) are collected in Table 2. Column I gives the number used throughout to identify the samples. The expansion of all the glasses, as shown in the curves that follow (Figs. 3 to I6), was very regular during the first 350 to $500^{\circ} \mathrm{C}$ of temperature. The mean expansions in this region are given in column 4 , and the temperature interval in column 3. Upon heating to higher temperatures the rate of expansion changed. With well-annealed glasses, the rate increased rapidly; with unannealed it first decreased for a time, then increased. The region in which this change occurred we shall call the critical region or the annealing temperature, because it agrees almost exactly with the annealing temperature determined by Tool and Valasek. Above the annealing temperature the samples expanded at the increased rate during the next $100^{\circ}$ rise in temperature. Column 5 gives 
the temperature interval of most rapid expansion, and column 6 the corresponding expansion coefficients, which are from two to seven times the coefficients of column 4 . Above the upper temperature of column 5, due to the softening of the material, a rapid decrease in the rate of expansion took place, followed by a contraction. The region where the change from expansion to contraction occurred is represented by the maximum ordinate of the curves, and we shall call the corresponding abscissa the softening temperature.

TABLE 2.-Mean Coefficient of Linear Expansion of Certain Glasses

\begin{tabular}{|c|c|c|c|c|c|}
\hline $\begin{array}{l}\text { (1) } \\
\text { No. }\end{array}$ & $\begin{array}{c}\text { (2) } \\
\text { Designation of glass }\end{array}$ & $\begin{array}{l}\text { Tempera- } \\
\text { ture in- } \\
\text { terval }\end{array}$ & $\begin{array}{l}(4) \\
\text { Coef- } \\
\text { ficient } \\
\times 10^{4}\end{array}$ & $\begin{array}{l}\text { (5) } \\
\text { Tempera- } \\
\text { ture in- } \\
\text { terval }\end{array}$ & $\begin{array}{l}(6) \\
\text { Coef- } \\
\text { ficient } \\
\times 10^{4}\end{array}$ \\
\hline $\begin{array}{r}1-2 \\
3 \\
4 \\
5 \\
6\end{array}$ & 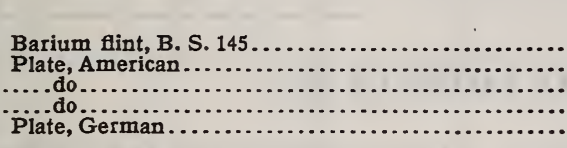 & $\begin{array}{l}{ }^{\circ} \mathrm{C} \\
22-494 \\
19-461 \\
20-508 \\
23-494 \\
21-496\end{array}$ & $\begin{array}{l}0.088 \\
.099 \\
.108 \\
.101 \\
.099\end{array}$ & $\begin{array}{l}{ }^{\circ} \mathrm{C} \\
519-550 \\
563-579 \\
540-560 \\
564-583 \\
564-589\end{array}$ & $\begin{array}{r}0.331 \\
.373 \\
.401 \\
.460 \\
.477\end{array}$ \\
\hline $\begin{array}{r}7 \\
8-15 \\
9 \\
10 \\
11\end{array}$ & $\begin{array}{l}\text { Plate, French } \\
\text { Light crown, B. S. } 103 \ldots \ldots \\
\text { Light crown, B. S. } 20 \ldots \ldots \\
\text { Borosilicate crown, B. S. } 94 \ldots \ldots \\
\text { Barium crown, B. S. } 87 \ldots \ldots\end{array}$ & $\begin{array}{l}21-513 \\
24-422 \\
22-426 \\
22-498 \\
23-499\end{array}$ & $\begin{array}{l}.094 \\
.104 \\
.102 \\
.090 \\
.090\end{array}$ & $\begin{array}{l}597-613 \\
494-507 \\
502-522 \\
539-562 \\
589-610\end{array}$ & $\begin{array}{l}.424 \\
.548 \\
.555 \\
.393 \\
.649\end{array}$ \\
\hline $\begin{array}{l}12 \\
13 \\
14 \\
15 \\
16\end{array}$ & 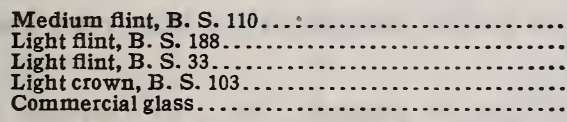 & $\begin{array}{l}23-402 \\
22-451 \\
23-420 \\
24-422 \\
23-445\end{array}$ & $\begin{array}{l}.097 \\
.088 \\
.076 \\
.104 \\
.107\end{array}$ & $\begin{array}{l}452-478 \\
494-512 \\
495-511 \\
496-505 \\
510-534\end{array}$ & $\begin{array}{l}.396 \\
.347 \\
.292 \\
.550 \\
.309\end{array}$ \\
\hline $\begin{array}{l}17 \\
18 \\
19 \\
20 \\
21\end{array}$ & 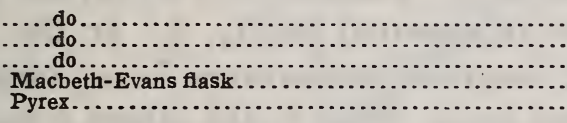 & $\begin{array}{l}22-452 \\
22-464 \\
21-474 \\
22-449 \\
21-471\end{array}$ & $\begin{array}{l}.103 \\
.102 \\
.102 \\
.069 \\
.036\end{array}$ & $\begin{array}{l}523-552 \\
544-557 \\
567-586 \\
552-571\end{array}$ & $\begin{array}{l}.318 \\
.316 \\
.454 \\
.151\end{array}$ \\
\hline $\begin{array}{l}22 \\
23 \\
24 \\
25 \\
26\end{array}$ & 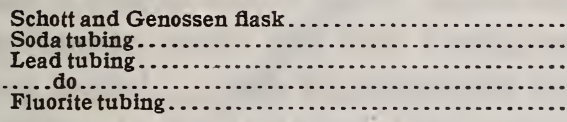 & $\begin{array}{l}19-414 \\
21-372 \\
21-338 \\
21-345 \\
22-364\end{array}$ & $\begin{array}{l}.056 \\
.120 \\
.091 \\
.096 \\
.098\end{array}$ & $\begin{array}{l}540-562 \\
506-525 \\
464-483 \\
457-477 \\
510-551\end{array}$ & $\begin{array}{l}.404 \\
.234 \\
.236 \\
.225 \\
.284\end{array}$ \\
\hline $\begin{array}{l}27 \\
28 \\
29 \\
30 \\
31\end{array}$ & 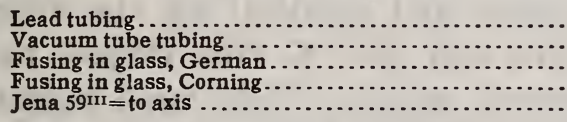 & $\begin{array}{l}21-333 \\
23-405 \\
23-383 \\
22-376 \\
38-522\end{array}$ & $\begin{array}{l}.097 \\
.116 \\
.090 \\
.083 \\
.064\end{array}$ & $\begin{array}{l}430-469 \\
509-545 \\
456-481 \\
460-485 \\
564-600\end{array}$ & $\begin{array}{l}.227 \\
.205 \\
.283 \\
.258 \\
.437\end{array}$ \\
\hline 32 & Jena 59 rr $\perp$ to axis..... & $22-491$ & .062 & $562-603$ & .452 \\
\hline
\end{tabular}

\section{CHEMICAL COMPOSITION}

Table 3 gives the chemical composition of the different glasses, those for the samples marked with an asterisk being based upon chemical analysis, while the rest give merely the batch composition. 
TABLE 3.-Chemical Composition of Certain Glasses

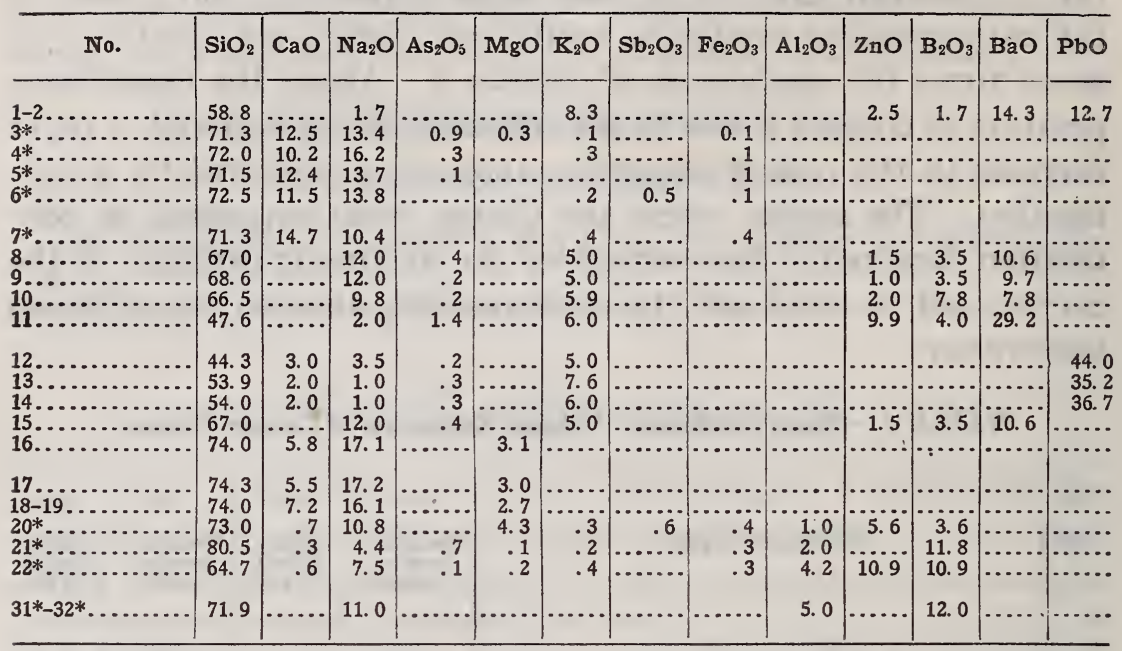

\section{FINAL VALUES OF $\frac{\Delta L}{L}$}

In the following curves (Figs. 3 to 16 , inclusive), the dilatation $\Delta L$ (in microns $(\mu)$ per centimeter) of samples of glass about $\mathrm{I} \mathrm{cm}$ long are plotted as ordinates, and the temperature (in degrees centigrade) as abscissas. The initial temperature was very nearly $20^{\circ} \mathrm{C}$ in each case.

Five separate determinations on a sample No. I of barium flint (B. S. 145) optical glass are represented in Fig. 3. In the first run the furnace was held at constant temperature for 15 minutes before each measurement was made, while in the others a steady heating was maintained throughout and the observations taken when every fifth fringe passed the reference mark. Below $510^{\circ} \mathrm{C}$ the expansion was nearly linear and identical for the different determinations. Between $5 \mathrm{IO}$ and $530^{\circ} \mathrm{C}$ (the critical range) the rate of expansion increased rapidly. This rapid expansion continued up to 580 to $590^{\circ} \mathrm{C}$. With further heating the rate decreased, contraction setting in at $608^{\circ} \mathrm{C}$. At $620^{\circ} \mathrm{C}$ the current was cut off and the sample allowed to cool. In three cases, after cooling to about $590^{\circ} \mathrm{C}$, then heating again, the sample expanded up to $610^{\circ} \mathrm{C}$, then contracted as before.

In the fourth and fifth determinations, observations were made of the contraction during the cooling process. When the temperature reached the critical region the ring suddenly broke away from the quartz plates, throwing the interferometer out of adjustment and making further measurements impossible. In the first 
curve for all points below $500^{\circ} \mathrm{C}$, the sample stopped expanding several minutes before the thermocouple came to constant temperature. The lag of the thermocouple caused this curve then to fall to the right of the rest, which were obtained from steady heating. At $523^{\circ} \mathrm{C}$ on this curve the ring continued to expand even after the thermocouple indicated a slight decrease in the temperature

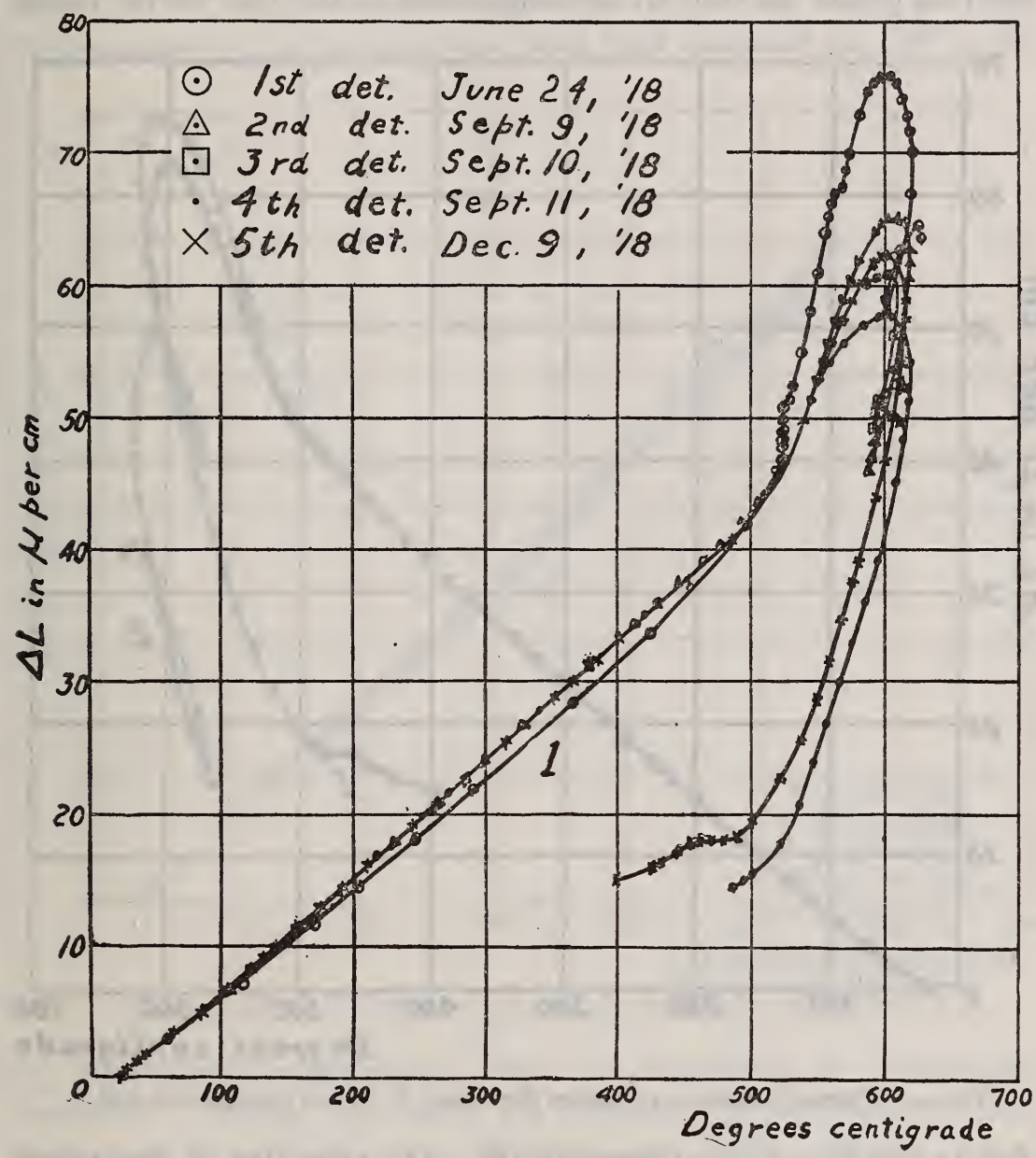

Fig. 3. -Thermal dilatation of barium flint glass, B.S. I45 (specimen I)

of the furnace. At $565^{\circ} \mathrm{C}$ the behavior was again similar to that at the lower temperatures.

Fig. 4 shows the expansions of two specimens of barium flint (Nos. $I$ and 2) which were cut from two blocks out of the same melt. Both samples show exactly the same expansion from 20 to $510^{\circ} \mathrm{C}$, a rapid increase at about $5^{1} 5^{\circ} \mathrm{C}$, then a contraction at about 
$600^{\circ} \mathrm{C}$. No. 2 , on being cooled to $570^{\circ} \mathrm{C}$ and then reheated, showed a contraction at approximately the same temperature as before. On being cooled a second time and a larger heating current applied, the contraction took place at a slightly increased temperature. For Fig. 5, sample No. 2 was heated to the critical temperature, then allowed to cool slowly. It returned to its original length at $160^{\circ} \mathrm{C}$, the separation of the two curves being

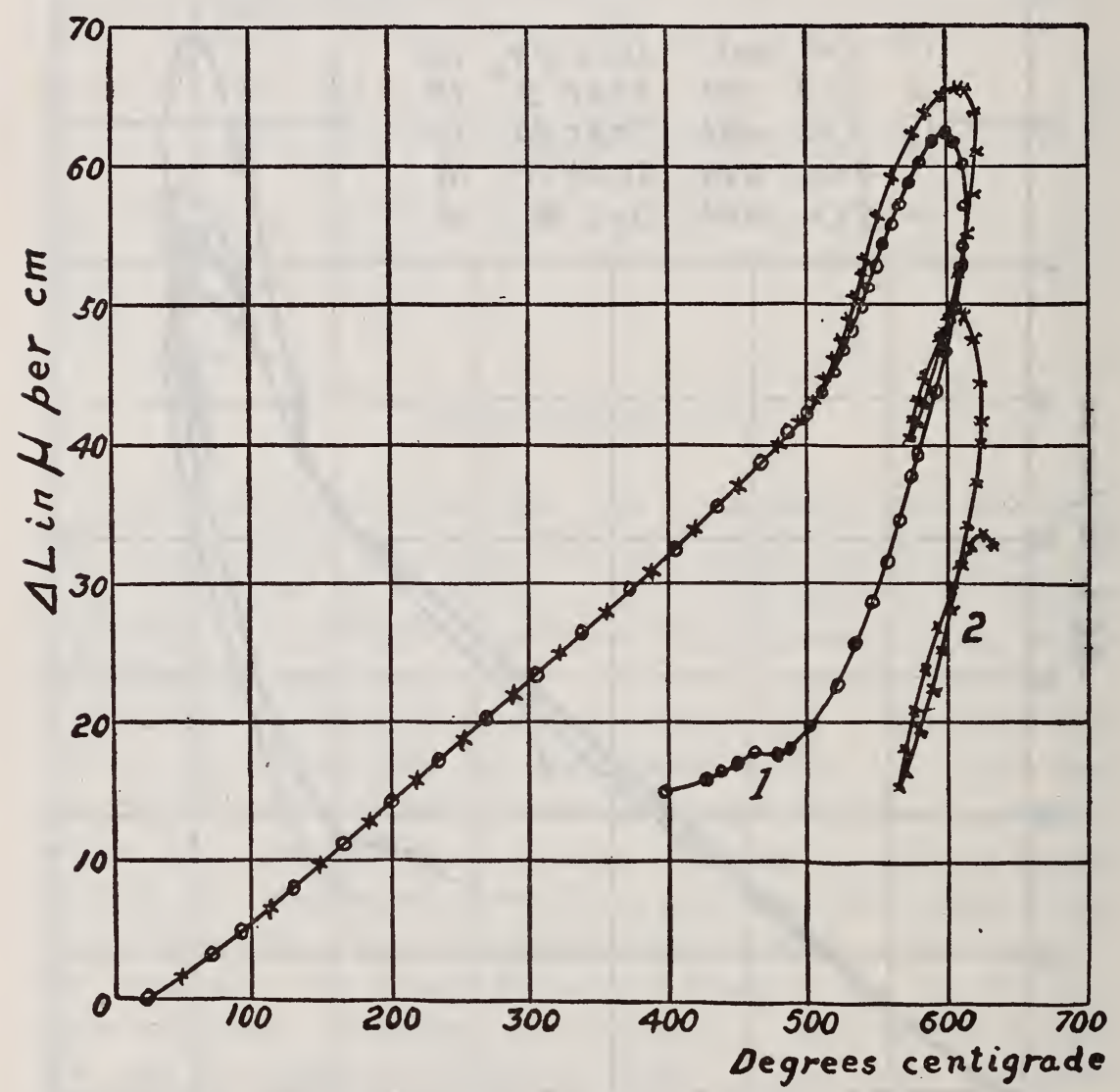

FIG. 4.-Thermal dilatation of barium flint glass, B.S. I45 (specimens I and 2)

due to the lag of the thermocouple. On reheating it was taken above the critical temperature and allowed to cool relatively rapidly. The sinuous shape of the second cooling curve shows the irregular contraction in passing through the critical range. This was accompanied by an unequal contraction of different parts of the ring as indicated by the rotation of the interference fringes. 
The expansion of a specimen (No. 3) of "Pittsburgh plate glass" is shown in curve 3, Fig. 6. The curve labeled "time of heating," which is plotted with time in minutes as ordinatesmagnitudes indicated on the right-shows the time that elapsed while the sample was being heated, cooled, or held at constant temperature. Raising the temperature at a uniform rate from 20 to $480^{\circ} \mathrm{C}$ in 80 minutes caused an expansion of $45 \mu$. The temperature of the sample was then held constant at $488^{\circ} \mathrm{C}$ for

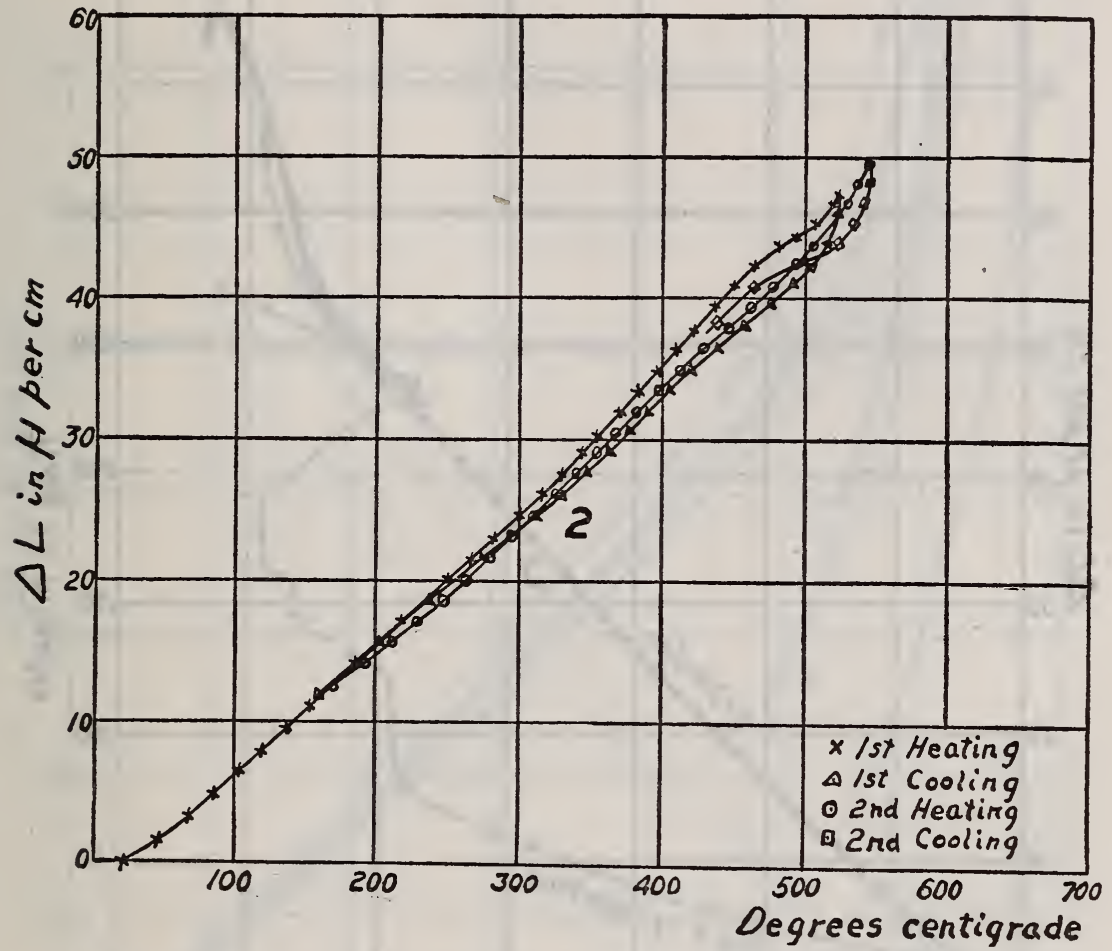

FIG. 5.-Thermal dilatation of barium flint glass, B. S. I45 (specimen 2)

35 minutes, during which time no expansion or contraction occurred. During the next 20 minutes the temperature was increased to $560^{\circ} \mathrm{C}$, where it was again held constant for I 5 minutes. Here an elongation of $3 \mu$ was observed. During the next ro minutes the temperature was raised to $588^{\circ} \mathrm{C}$, and, upon being held constant for 25 minutes, the sample showed a contraction or shortening of $3 \mu$. The heating current was then reduced so that the sample cooled to $470^{\circ} \mathrm{C}$ in 45 minutes. Upon increasing the current, the sample expanded over that part of 
the curve represented by the circles, until the temperature reached $624^{\circ} \mathrm{C}$, where contraction began.

The expansions of four different kinds of plate glass, Nos. 4 to 7 , are represented by the curves in Fig. 7 . These samples were heated at the same rate and all showed practically linear expansion up to $500^{\circ} \mathrm{C}$. All the samples showed a rapid increase in expansion above the annealing region, which increase was fol-

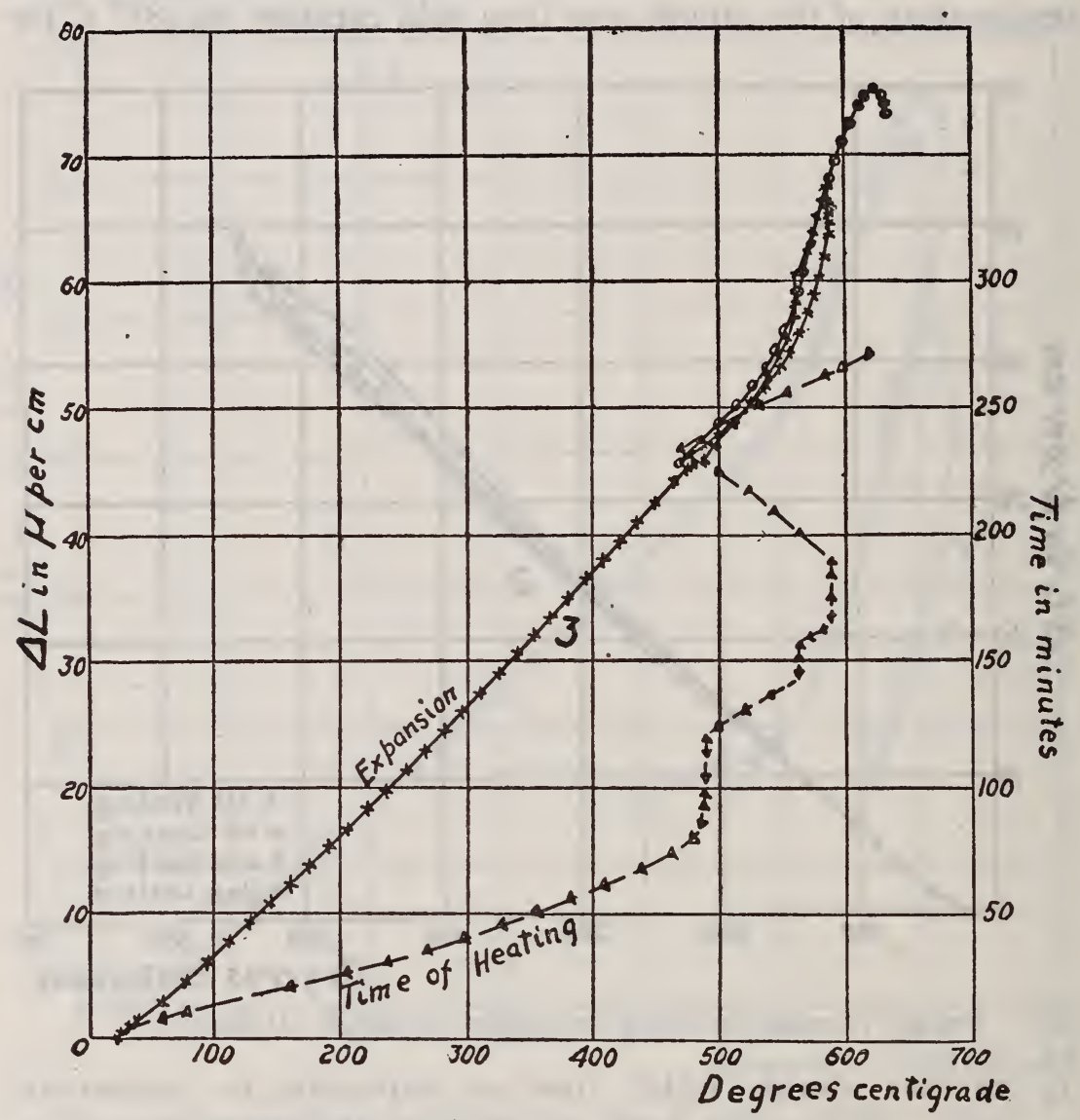

FIG. 6.-Thermal dilatation of plate glass (specimen 3)

lowed by a contraction above the softening temperature. The temperatures at which these variations took place were different for the different glasses. In each case observations were made on the cooling curve until the ring broke away from the quartz plates. It should be noticed that with all four samples this rupture occurred in the critical region. These samples fused so firmly to the quartz plates that the bearing points of the ring 
were broken and pieces of quartz $3 \mathrm{~mm}$ across were sheared from the surface of the plates.

By referring to Table 2 it will be noticed that the samples 3 , 5 , and 6 , which show almost the same expansion, are very nearly identical in their chemical composition. No. 4, which has a higher $\mathrm{Na}_{2} \mathrm{O}$ and a lower $\mathrm{CaO}$ content, has a higher rate of ex-

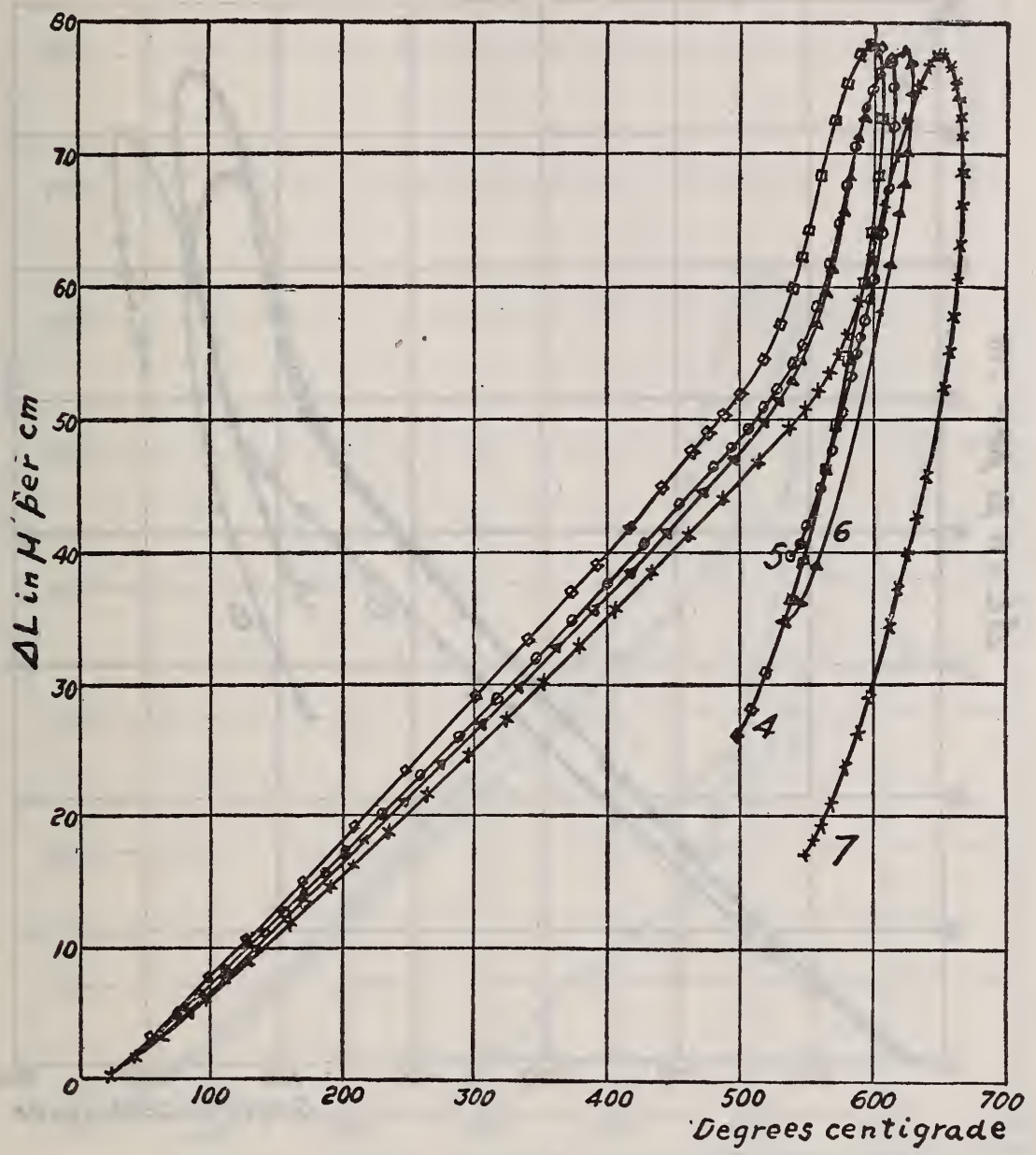

FIG. 7.-Thermal dilatation of plate glass (specimens 4, 5, 6, and 7)

pansion and a lower critical temperature; while in the case of No. 7 , with a lower $\mathrm{Na}_{2} \mathrm{O}$ and a higher $\mathrm{CaO}$ content, the reverse is true.

Figs. 8, 9, and Io represent the expansion of nine different kinds of optical glass made at the Pittsburgh laboratory of the Bureau of Standards. These curves show the rapid increase in the rate 
of expansion, followed by a contraction above the softening temperatures. The critical temperature varied from $440^{\circ} \mathrm{C}$ in the case of No. $I 2$ to $570^{\circ} \mathrm{C}$ with sample No. II. Likewise, the softening temperature varied in the same sequence from $520^{\circ} \mathrm{C}$ with sample No. $I 2$ to $660^{\circ} \mathrm{C}$ with No. $I I$. In the case of sample No. I2, Fig. 9, the effect of the fracture in cooling was so slight

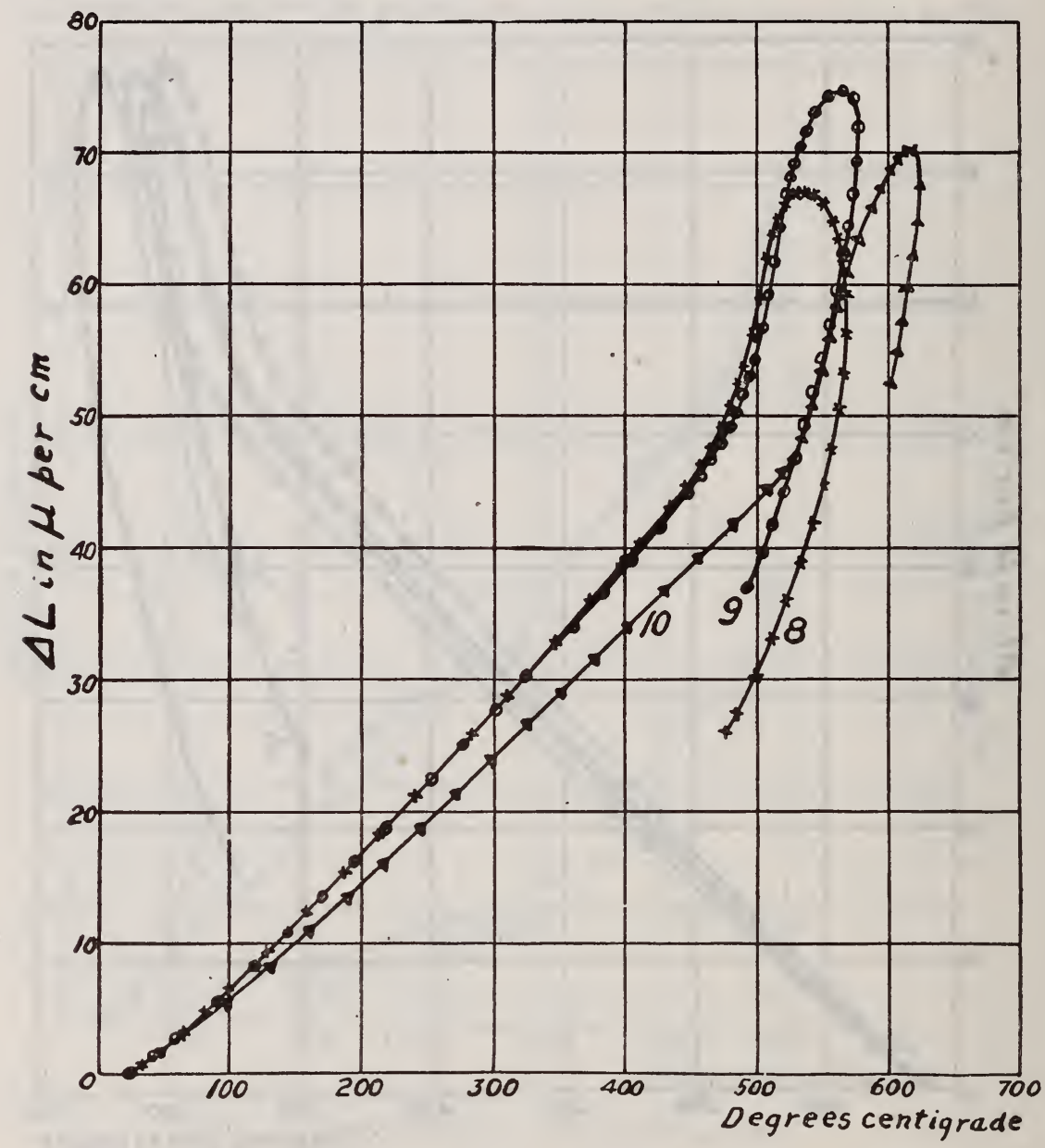

FiG. 8.-Thermal dilatation of optical glass (specimens 8, 9 , and Io)

as to permit observations to be taken down to $280^{\circ} \mathrm{C}$. The cooling curve is very nearly parallel to the heating curve, and the separation of the two shows a permanent shortening of the sample.

Observations made of the expansion of four samples of commercial glass are represented by the curves in Fig. II. These show the same general characteristics as those of previous experi- 
ments. In the case of sample No. 16 , the lag of the thermocouple was increased by a much higher rate of heating. Sample No. $I 7$ was brought to a steady temperature at $530^{\circ} \mathrm{C}$ and heated at a relatively slow rate during the remainder of the experiment.

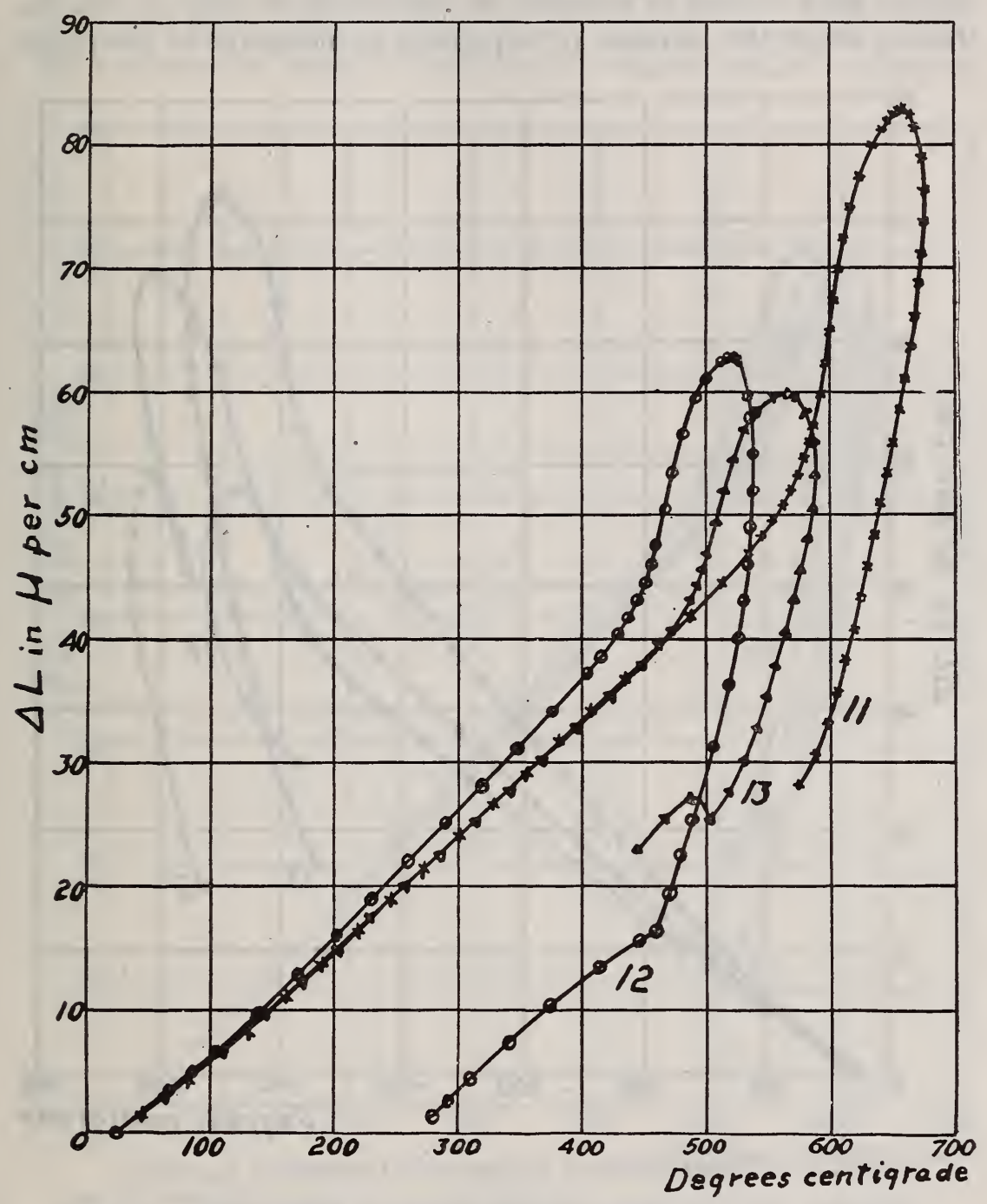

FIG. 9.-Thermal dilatation of optical glass (specimens II, I2, and I3)

Glasses 20, 2I, and 22, Figs. I 2 and 13 , are samples of chernical glassware obtained by cutting ring sections from Florence flasks. Sample No. 21 (Pyrex) has a high silica content and a low expansion, but at the higher temperatures it follows the same general characteristics of other kinds of glass. No. 20 (Macbeth-Evans) 
showed a slight decrease in the expansion between 450 and $550^{\circ} \mathrm{C}$, followed by an exceptionally large and rapid increase in expansion. This decrease in the rate of expansion in the temperature region 400 to $500^{\circ} \mathrm{C}$, which is doubtless due to the unannealed condition of the glass, is also in evidence in the curves of Nos. 23 and 24; but in these the increase in expansion is moderate as compared

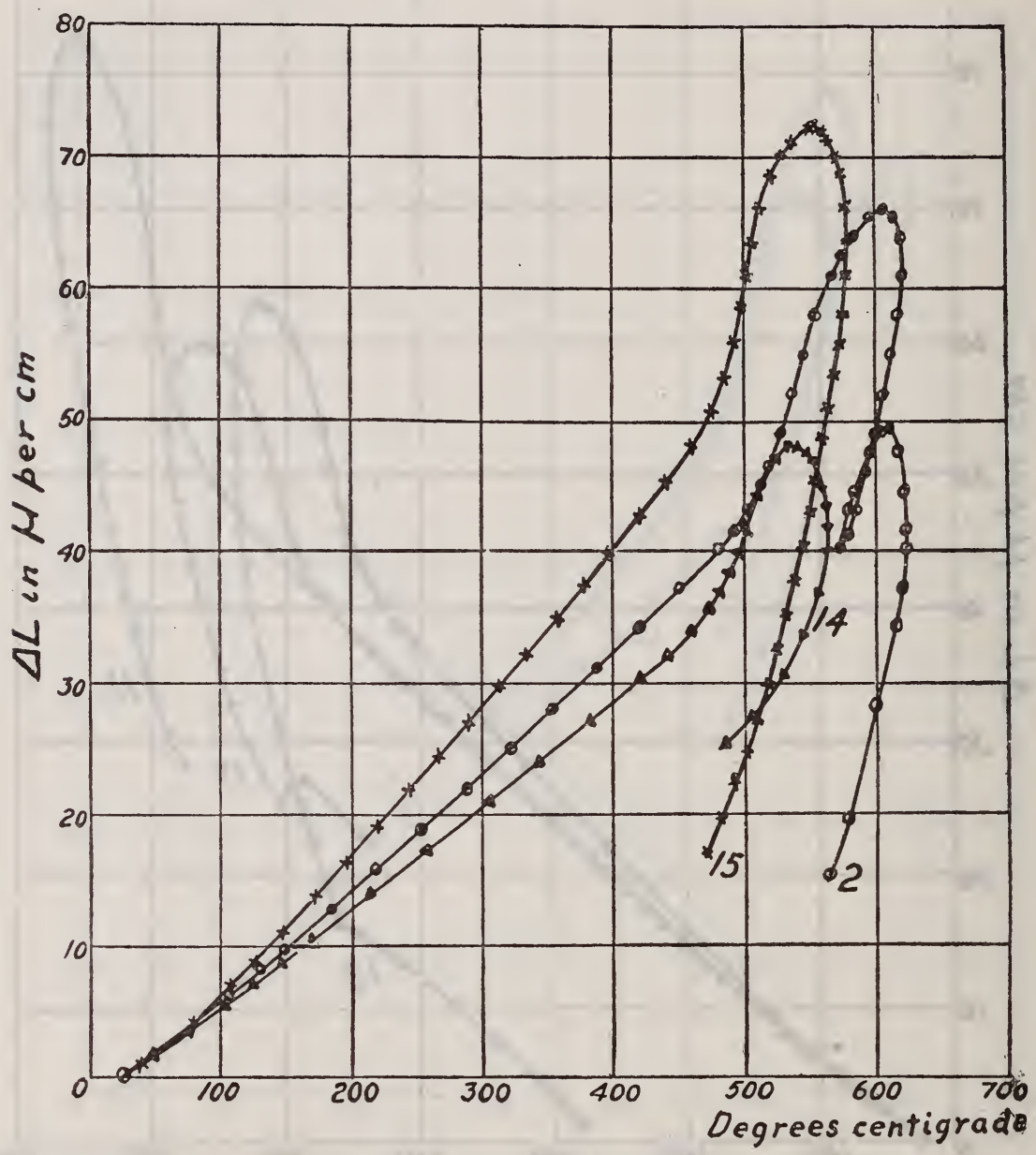

FIG. I0.-Thermal dilatation of optical glass (specimens 2, I4, and I5)

with No. 20. The first measurements on the expansion of No. 22 Jena are shown by the crosses in Fig. 13. In this case the glass was heated to $445^{\circ} \mathrm{C}$, held constant at this point about 20 minutes, then allowed to cool. The separation between the heating and cooling curve represents the double lag of the thermocouple behind the sample. The second measurements, made the fol- 
lowing day, are represented by the circles. Upon passing the temperature $445^{\circ} \mathrm{C}$, the sample contracted slightly, then continued to expand at its previous rate. No. 23 was cut from a length of soda glass tubing and No. 24 from lead glass tubing. Both had been cooled quickly in air and put under high strain, the existence of which is indicated by the decrease in their ex-

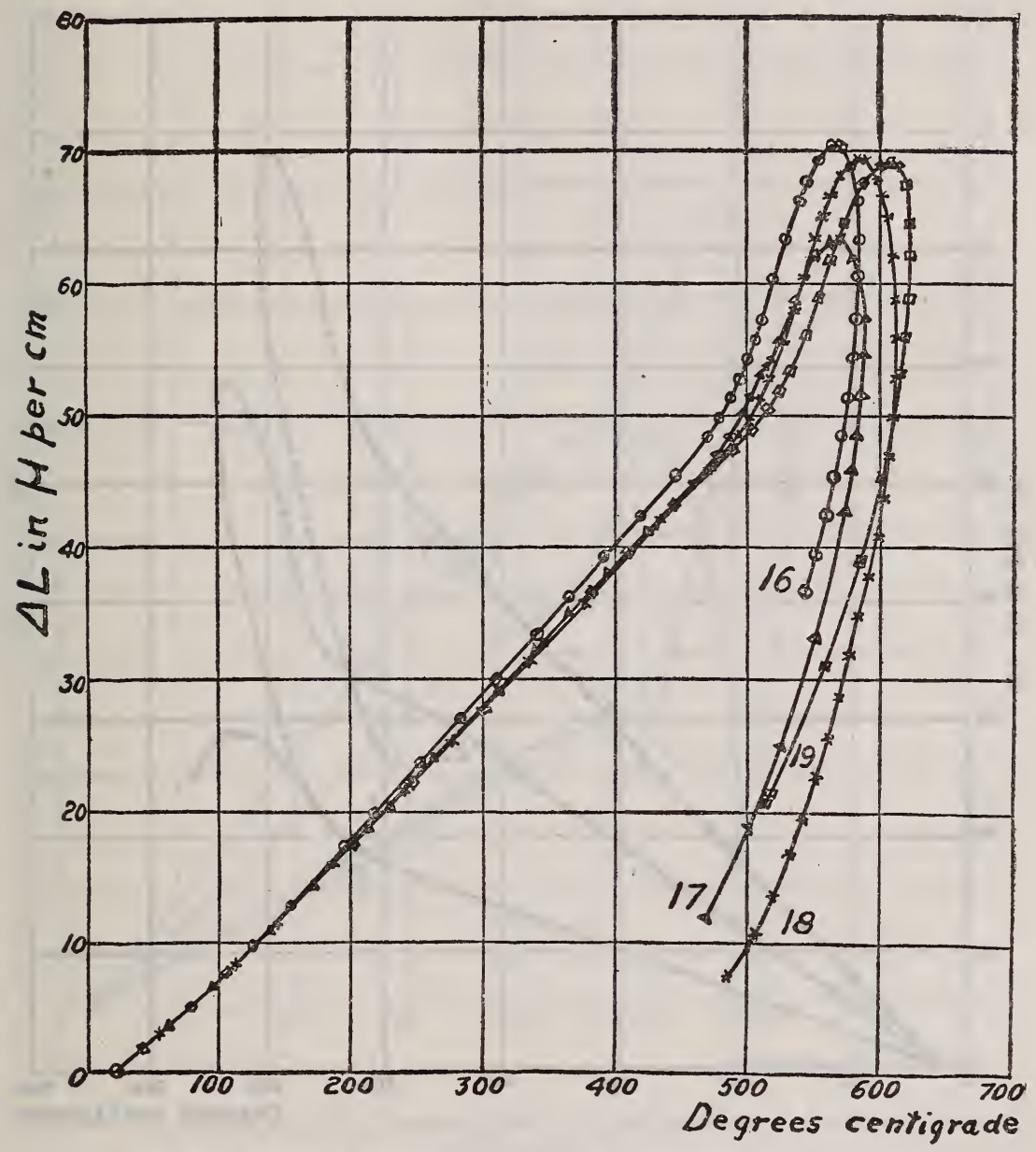

FIG. II.-Thermal dilatation of commercial glass (specimens I6, I7, I8, and I9)

pansion rate in the critical region. With No. 24 the heating was continued approximately $70^{\circ}$ beyond the softening point, the rise in temperature being accompanied by a rapid increase in the rate of contraction. Of those represented by Fig. I4, No. 25 was cut from a length of soda lime tubing of 2 I per cent lead content, No. 26 from white fluorite tubing of low lead content, and No. 
27 from a potash lead tubing of 20 per cent lead. All of these samples showed first a decrease, then an increase in the rate of expansion in the critical region.

The curves in Fig. I 5 represent the thermal expansion of glass (Nos. 28, 29, and 30) recently used in making rare-gas lamps at the Bureau of Standards. Many of the lamps cracked near the

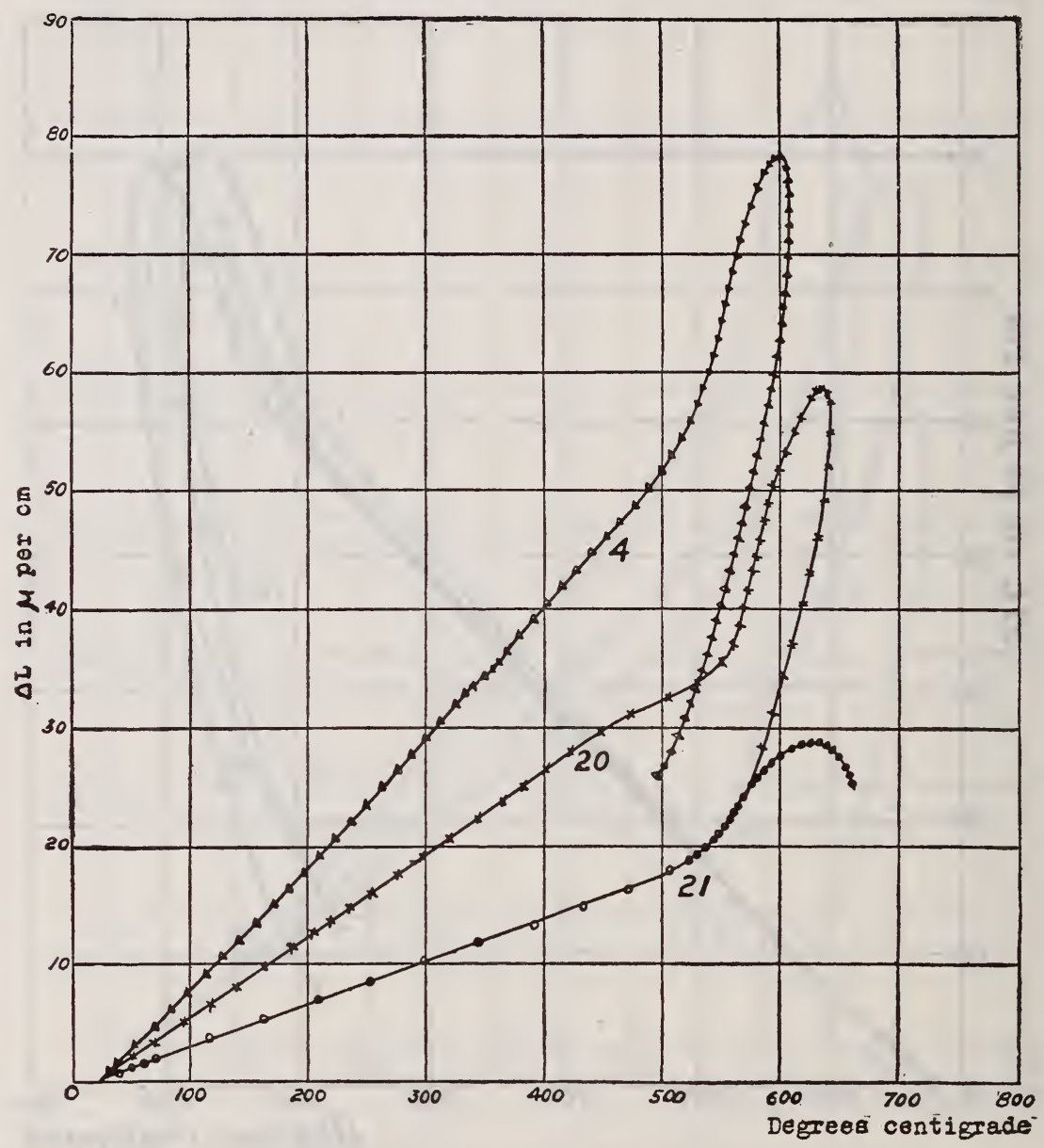

FIG. 12.-Thermal dilatation of chemical glassware (specimens 4, 2O, and 2I)

platinum electrodes, and it was thought that the Corning sealing-in glass might have a different thermal expansion from the German glass previously used. Both kinds, however, were found to have almost identical thermal expansions, as shown by curves 29 and 30. The curves indicate that these were lead glasses very similar to No. 24. The expansion of the tubing used for making the 
lamps, however, as shown by curve 28 , has a thermal expansion, annealing temperature, and softening temperature very different from these-which accounts for the breakage of the lamps.

An interesting condition is shown by the results of Fig. I6. Curve $3 I$ represents the longitudinal and 32 the radial expansion

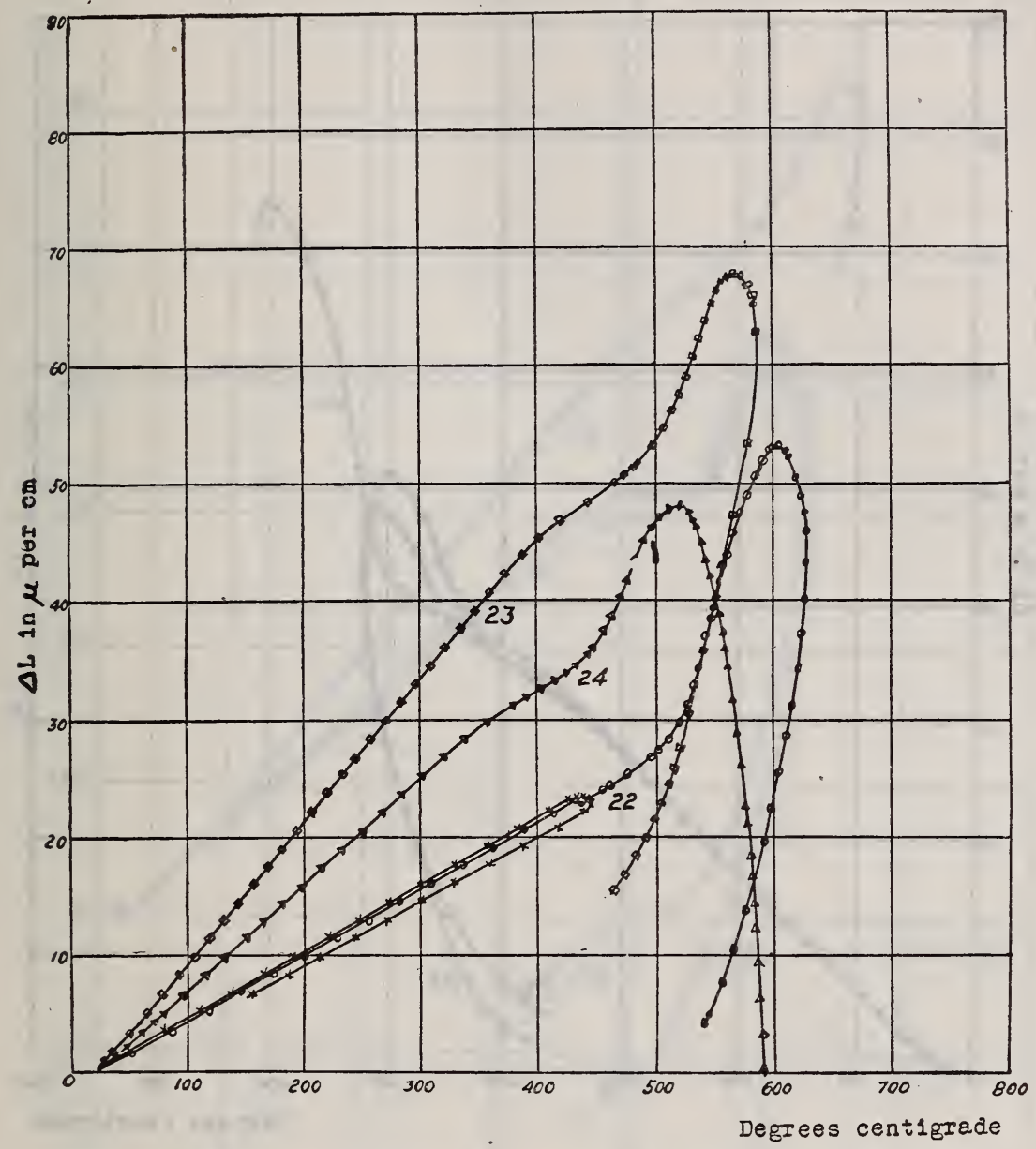

Fig. I3.-Thermal dilatation of chemical glassware and commercial glass (specimens 22, 23, and 24)

of sections cut from the capillary of a Jena $59^{\mathrm{III}}$ thermometer, graduated to read $560^{\circ} \mathrm{C}$. They show that $500^{\circ} \mathrm{C}$ is the upper limit at which this kind of a thermometer could be used without injury. As stated before, Holborn and Grüneisen found a permanent contraction in this glass after it had been heated to $550^{\circ} \mathrm{C}$. Our curves show that a definite contraction is to be expected, 
for $550^{\circ} \mathrm{C}$ is certainly within the critical region. With both samples heated at the same rate, No. 32 continued to expand $40^{\circ}$ beyond the softening temperature of No. $3 I$. The permanent shortening of $20 \mu$ in No. $3 I$ after it was heated to $640^{\circ} \mathrm{C}$ is shown by the separation of the heating and cooling curves.

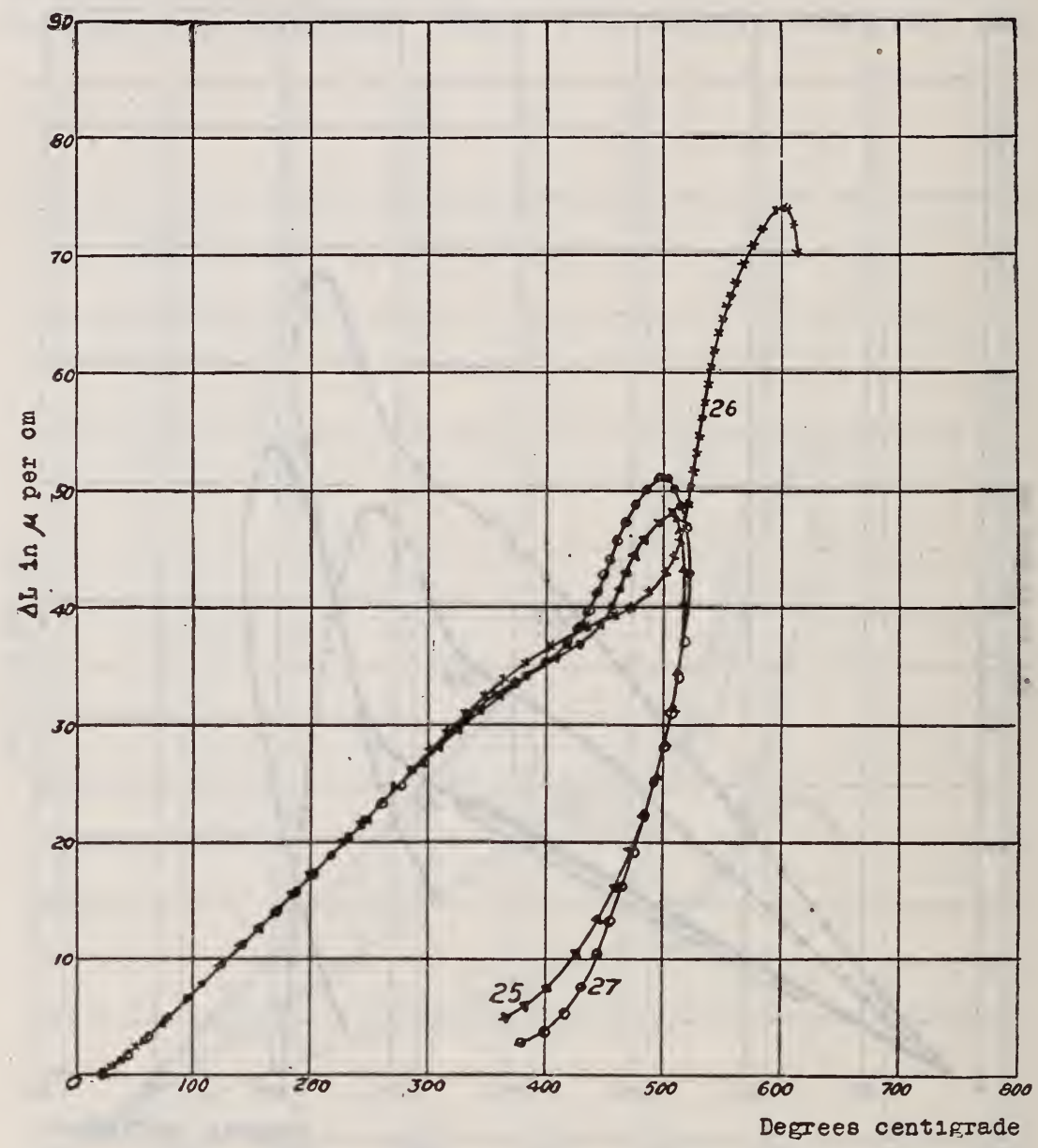

FIG. 14.-Thermal dilatation of commercial giass (specimens 25, 26, and 27)

\section{DIMENSIONAL CHANGE ABOVE THE CRITICAL TEMPERATURE}

The measurements described in the preceding sections show that, below the critical range, glass has a regular expansion and contraction, retains its dimension when held at a given temperature for a long period, and returns to its original length on being carried through a temperature cycle; that is, it may be considered as a 
solid. Upon passing through the critical region-that is, above the first bend in the curves-it seems to soften or become viscous. When held at a constant temperature in the critical region, there is first an expansion, then a slow contraction. This took place

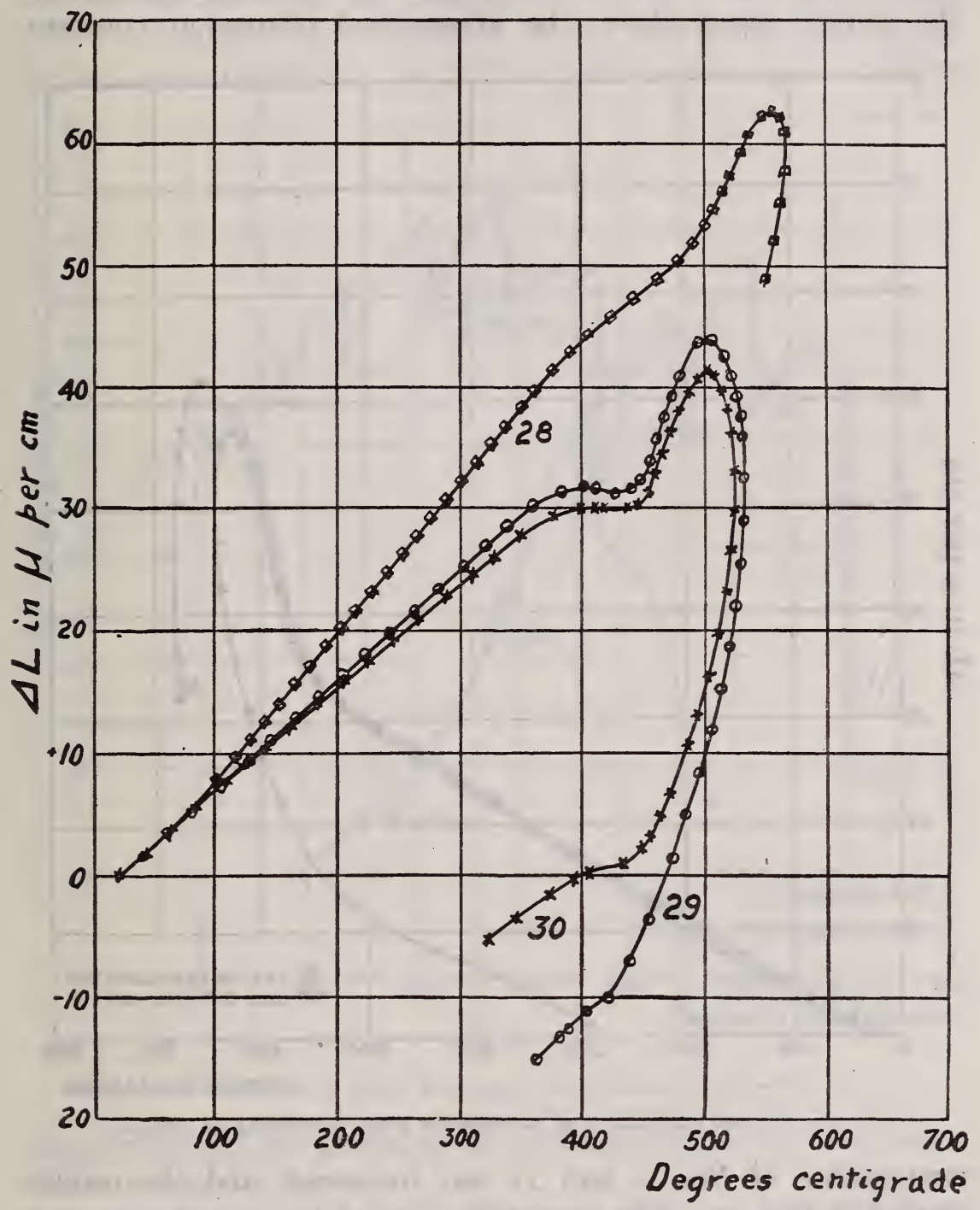

FIG. I5.-Thermal dilatation of vacuum tube glass (specimens 28, 29, and 30)

at $525^{\circ} \mathrm{C}$ in sample No. $I$ and $560^{\circ} \mathrm{C}$ in No. 3. When held constant at points above the critical region, the rate of contraction increases with the temperature. The highest part of the curves, which we have called the softening region, gives the temperature 
at which the contraction due to the softening is just sufficient to overcome the expansion due to the heating. At higher temperatures contraction predominates, as indicated by the rapid drop in the curves.

To obtain some data on the actual rate of contraction above the critical temperature, the dimensional change at constant

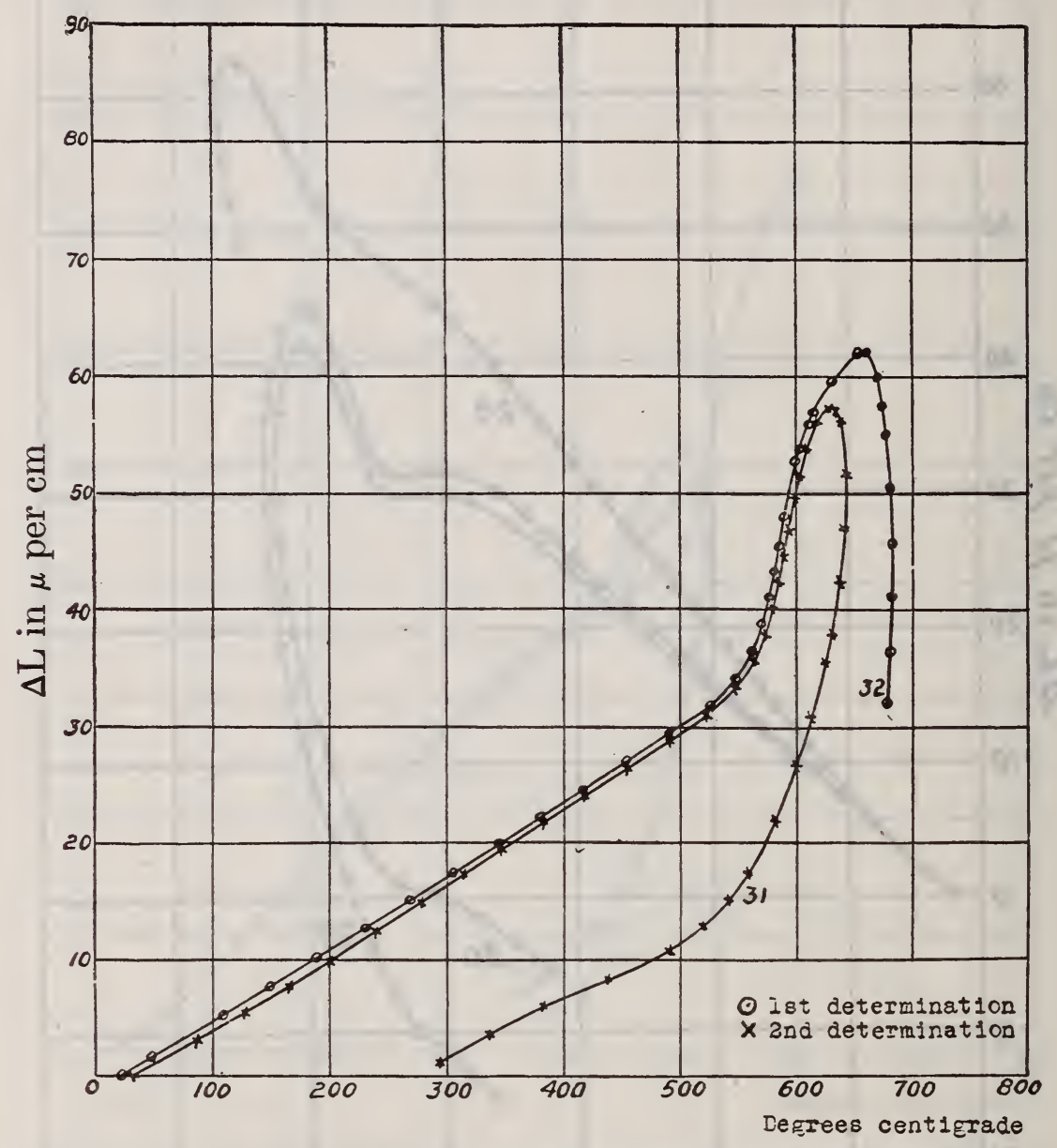

FIG. I6.-Thermal dilatation of thermometer glass (specimens $3^{I}$ and 32 )

temperature of Nos. 2 and II was measured, and the results plotted in Fig. I7. The ascending parts of the curves represent the expansion during heating, while the descending parts show the contraction when the temperature was held constant for the indicated number of minutes. From determinations made in this way the rates of contraction of Nos. 2,8, and I I were computed 
for the different temperatures, and the results plotted in Fig. I8, with rate of contraction in microns per minute as ordinates and the temperature in degrees centigrade as abscissas. A comparison of these curves with those representing the thermal expansion reveals the fact that the contraction rate is very small, about $0.01 . \mu$ per minute, in the critical region; that it increases slowly in the range containing the high-expansion rate, and increases

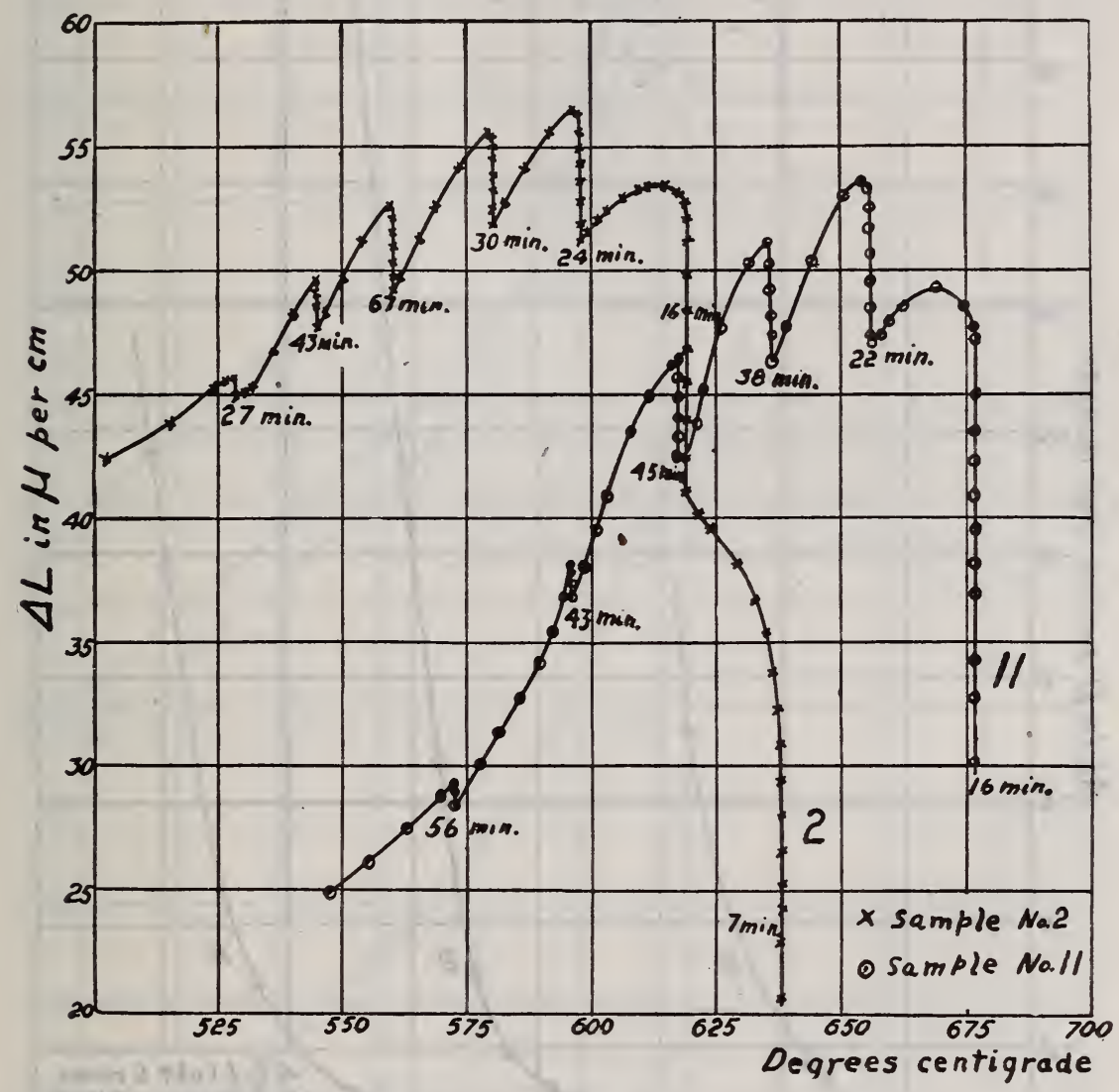

Fig. 17.-Contraction of glass at constant temperature (specimens 2 and II)

rapidly beyond the temperature corresponding to the maximum of the expansion curve.

Considering the nature of this contraction, we find that it is irreversible; that is, the sample undergoes a permanent decrease in length as shown by the cooling curves. This shrinking may be due to several causes. The most natural explanation is that the sample settles under its own weight plus that of the cover plate. Since, however, the weight was only a few tenths of a gram per 
square millimeter, and since samples of different sizes and shapes did not differ as much as they should, we were led to believe that the weight was not the only cause of the contraction. To test this point further, R. L. Coleman and J. O. Eisinger, of the expansion laboratory of the Bureau of Standards, determined the expansion

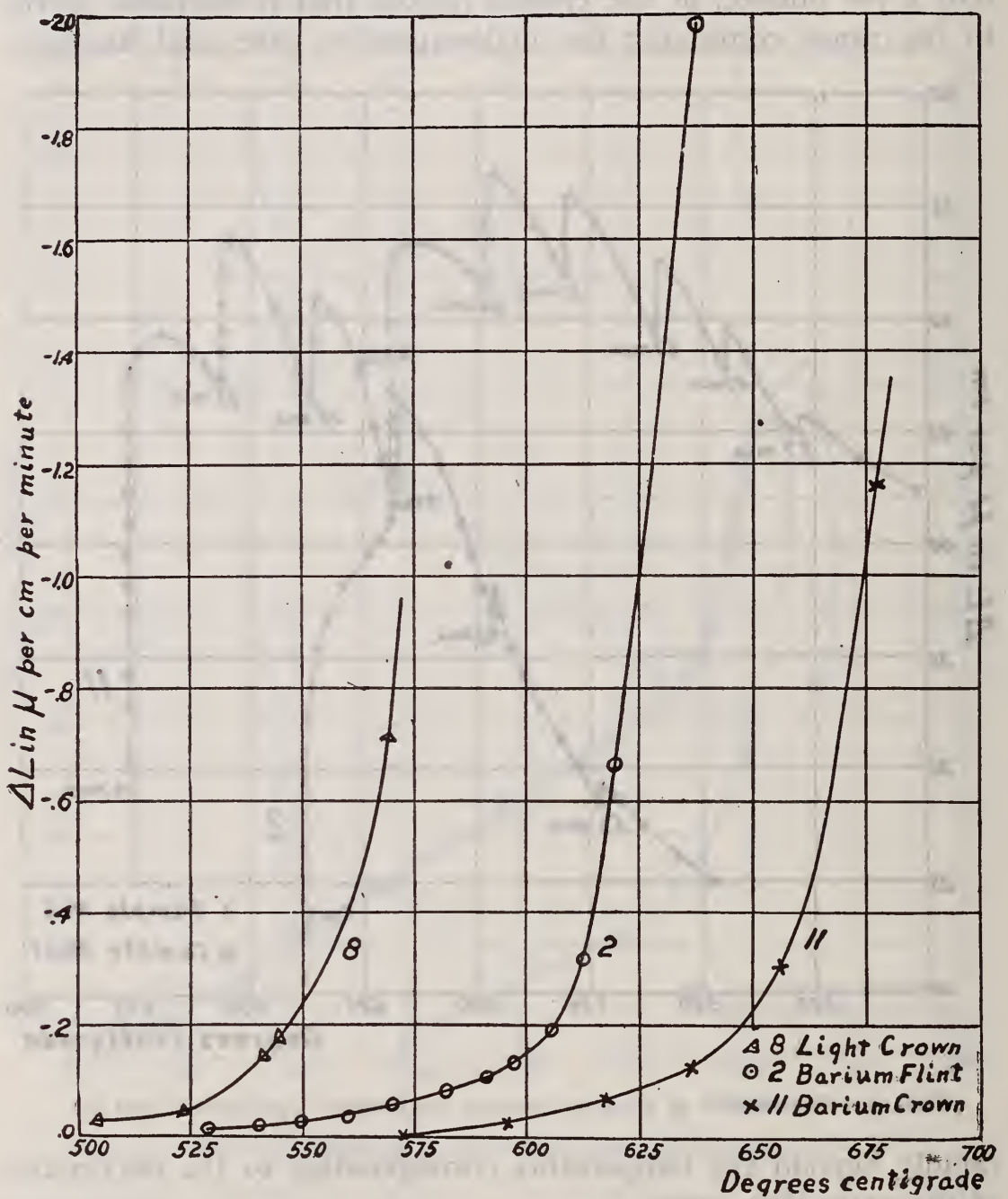

FIG. I8.-Rate of contraction of glass (specimens 2, 8, and II)

of a glass rod $30 \mathrm{~cm}$ long and $\mathrm{I} \mathrm{cm}$ in diameter by a micrometric method. For this purpose, the sample was mounted horizontally on a sheet of asbestos inside a porcelain tube and heated in the electric furnace described and used by Souder and Hidnert. ${ }^{10}$ 
Their measurements were made with micrometer microscopes sighted upon wires hung from transverse grooves cut near the ends of the rod. In the first determination, Fig. 19, the sample showed in the critical range a decrease, followed by a rapid increase, in the

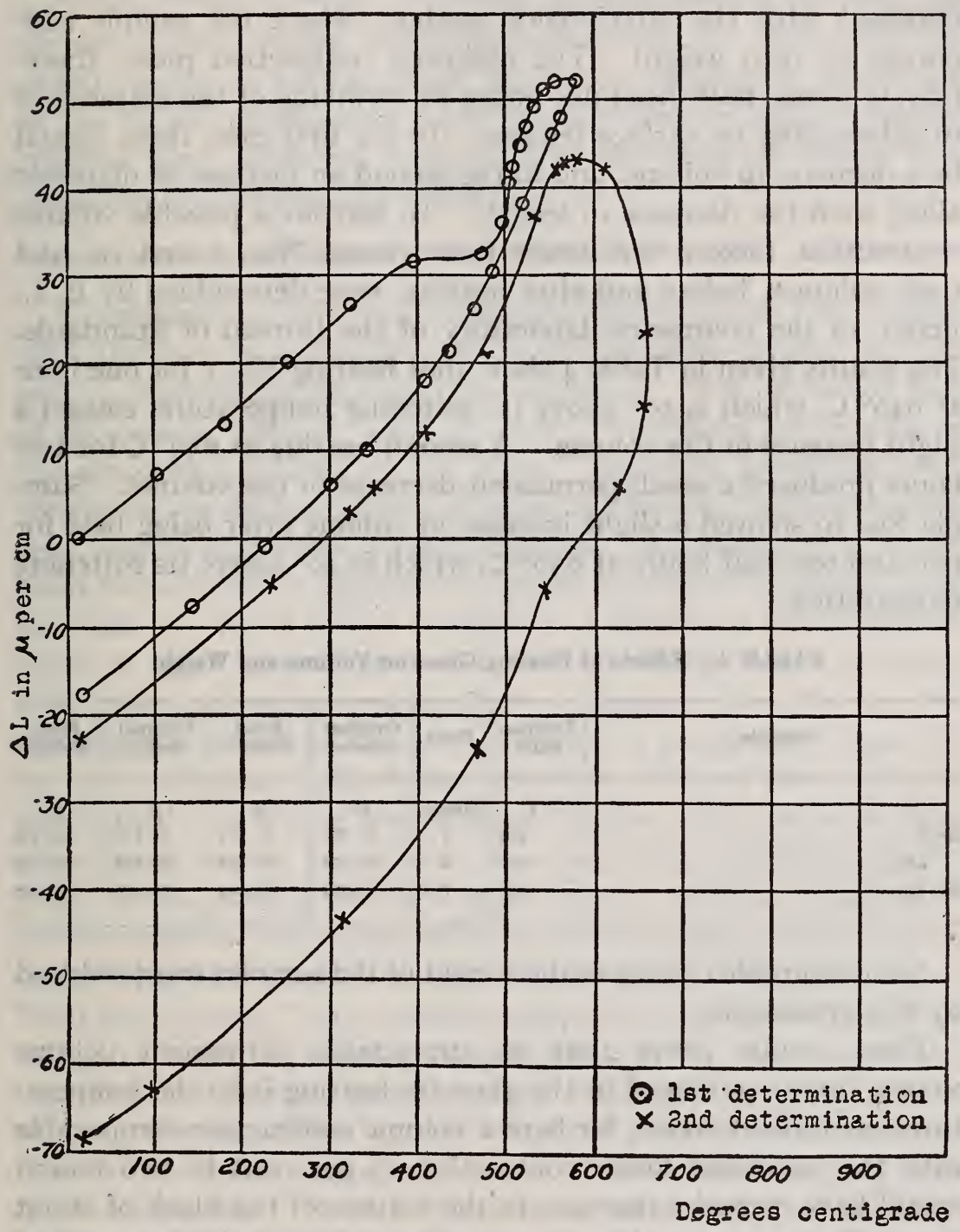

Fig. 19. -Thermal dilatation by the micrometric method (specimen, commercial glass)

expansion rate as found in unannealed glasses. At the softening temperature it stopped expanding and contracted slightly. On returning to the original temperature, notwithstanding its horizontal position, a permanent contraction of $0.6 \mathrm{~mm}$ was registered. 
In the second determination heating the sample $100^{\circ} \mathrm{C}$ above the softening point caused it to contract rapidly and show a permanent shortening of $1.5 \mathrm{~mm}$. Thus in this experiment, although the rod was free to expand in a horizontal direction, uninfluenced by the force of gravity, a contraction took place similar to that obtained with the interference method, where the sample supported its own weight. The observed contraction must, therefore, it seems, have been due either to shrinking of the material or to spheroiding by surface tension. In the first case, there should be a decrease in volume, and in the second an increase in diameter along with the decrease in length. To test for a possible volume contraction, blocks were made from glasses Nos. $I$ and $I O$, and their volumes, before and after heating, were determined by $\mathrm{E}$. $\mathrm{L}$. Peffer, of the volumetric laboratory of the Bureau of Standards. The results given in Table 4 show that heating No. I for one hour at $640^{\circ} \mathrm{C}$, which is $30^{\circ}$ above its softening temperature, caused a slight increase in the volume. A second heating at $650^{\circ} \mathrm{C}$ for two hours produced a small permanent decrease in the volume. Sample No. Io showed a slight increase in volume after being held for two and one-half hours at $650^{\circ} \mathrm{C}$, which is $40^{\circ}$ above its softening temperature.

TABLE 4.-Effects of Heating Glass on Volume and Weight

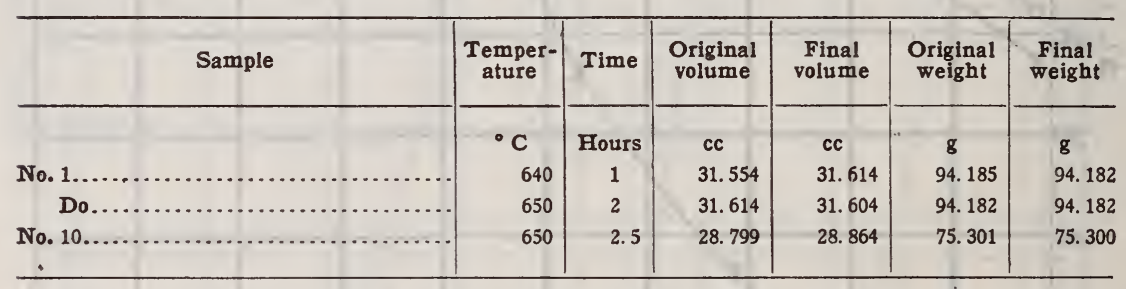

No measurable change in the weight of the samples was produced by this treatment.

These results prove that no appreciable permanent volume contraction is produced in the glass by heating it to the temperatures mentioned above, for here a volume contraction comparable with the measured linear contraction ( 3 per cent in two hours) would have caused a decrease in the volume of the block of about $3 \mathrm{cc}$. The permanent linear contraction, which Callender ascribed to a change in structure of the material, must, therefore, be due to a spheroiding of the sample. To test this last assumption, three sections I cm long and $0.5 \mathrm{~cm}$ in diameter were cut from the capillary of a thermometer and their longitudinal expansion, rep- 
resented by curve $3 I$, Fig. I6, measured. The radial expansion of three more sections from the same capillary is represented by curve 32. These curves show that, with both sets of samples heating at the same rate, the softening temperature of No. 32 was $40^{\circ}$ higher than for No. $3 I$. With the longitudinal samples, the surface tension works with gravitational force, while with the radial samples it works against that force, causing the expansion at the higher temperature. Of course, when the radial samples reached their softening temperature, the surface tension was insufficient to support the weight.

\section{COMPARISONS OF DIMENSIONAL CHANGES AND HEAT ABSORPTION}

A comparison of the heat-absorption curves of Tool and Valasek with the thermal expansion curves for the same glasses, Nos. II and $I_{3}$, is readily made from Figs. 20 and $2 \mathrm{I}$. The ascending part of the curves, marked "heat absorption," indicates an increase in the absorption of heat by the glass. The heat absorption commences in the critical region, increases in the range of rapid expansion, and falls off in the softening region. An equally good agreement between the two effects was found for the other glasses listed in Table 2. W. P. White ${ }^{17}$ observed a difference in the specific heats of glass above and below this region, and it is probable that other properties would show a change. In order to test the effect on the refractive index, we are now preparing to measure, by an interference method, the refractive index of glass plates in the critical and higher temperature regions. The cause of these phenomena may be the melting of some of the constituents of the glass, or the melting of the compound as a whole. Whether or not we conclude that glass melts, or starts to melt, in the critical region depends mostly on our definition of solid and liquid. Feild and Royster ${ }^{18}$ give melting points for their silicates between I 200 and $1400^{\circ} \mathrm{C}$., defining the melting point as the temperature at which the fluidity becomes zero. Our measurements on the rate of softening (Figs. I 7 and 18 ) show that the glass starts to flow at the critical region, about $500^{\circ} \mathrm{C}$., the rate increasing with the temperature. These values can be expressed, as were those of Tool and Valasek obtained from the strip-bending experiment, by Twyman's equation $T_{\theta}=T_{0} e\left(\frac{\theta_{0}-\theta}{k}\right)$, where $T_{\theta}$ and $T_{0}$ are the "relaxation" times at temperatures $\theta$ and $\theta_{0}$, and $k$ is a 
constant. Since the fluidity increases exponentially, any determination of the melting point will depend on experimental method and sensitivity of the apparatus. Instead, therefore, of speaking of a melting point, it seems better to say that glass has a softening range which can be located by the variations in the different properties.

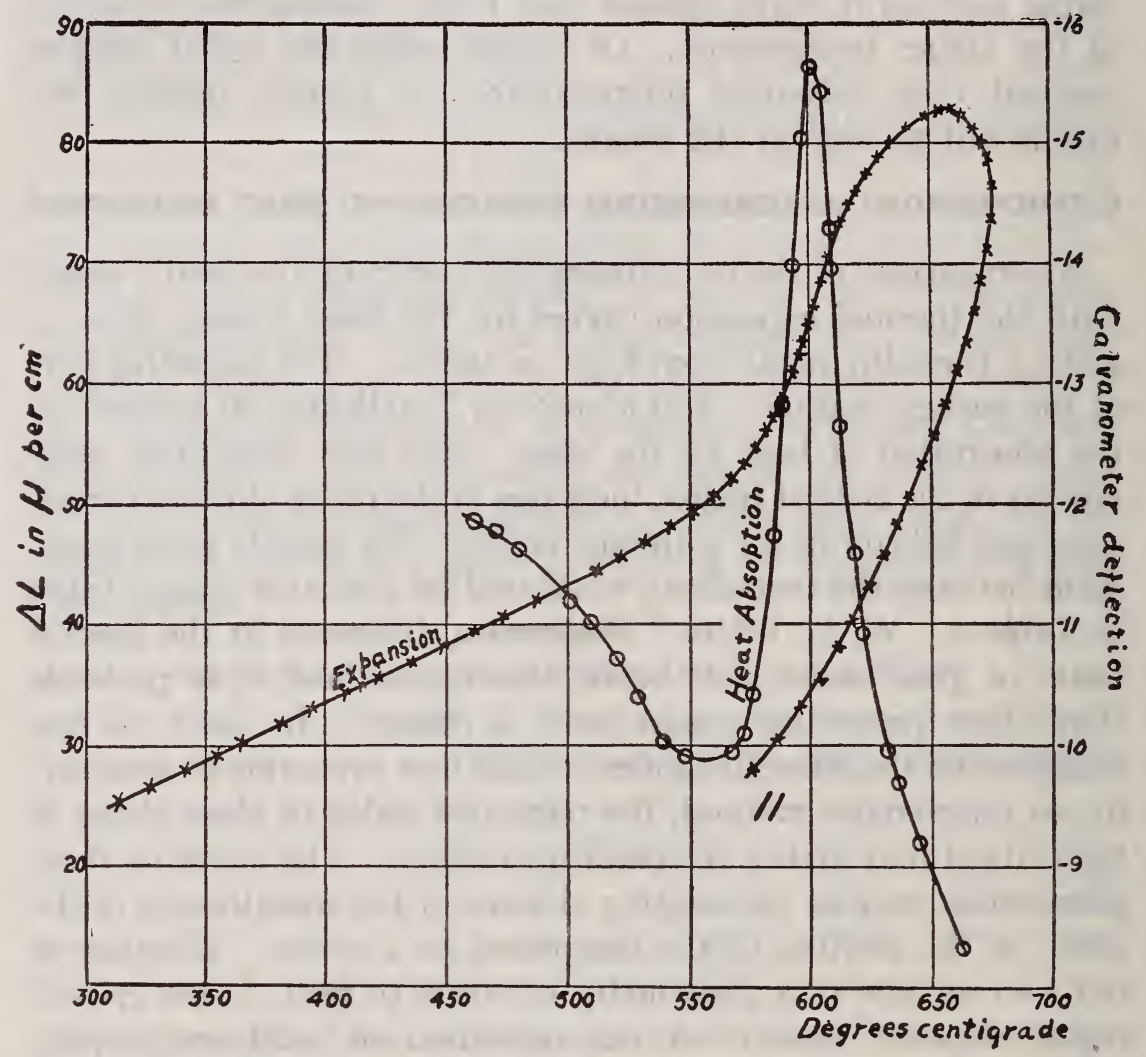

FIG. 20.-Thermal dilatation and heat absorption of barium crown glass, B. S. 87 (specimen II)

\section{ANNEALING TEMPERATURE}

The rate of expansion of glasses Nos. 23 to 30 decreased on approaching the critical region and Nos. 29 and 30 show even a contraction. These samples, Nos. 23 to 30 , were all taken from badly strained pieces of commercial tubing, and it is very probable that the decrease in expansion rate was due to the presence of these strains, because the well-annealed glasses Nos. I to 22 do not show a decrease. The same behavior was observed by M. So 
(see footnote 6) for annealed and unannealed rods $\mathrm{I}$ to $2 \mathrm{~mm}$ in diameter. For unannealed glass, he found contractions in the critical region, but these disappeared after the glass had been annealed.

It seems probable that most of the strains that exist in a piece of glass are introduced when it cools through the critical region. When cooled rapidly the outer shell reaches the critical temperature first and hardens or solidifies, while the inner part still contracts at the rapid rate which puts the outer shell under a high tension? When the sample is reheated the outer shell softens first, and the tension of the inner part causes a contraction.

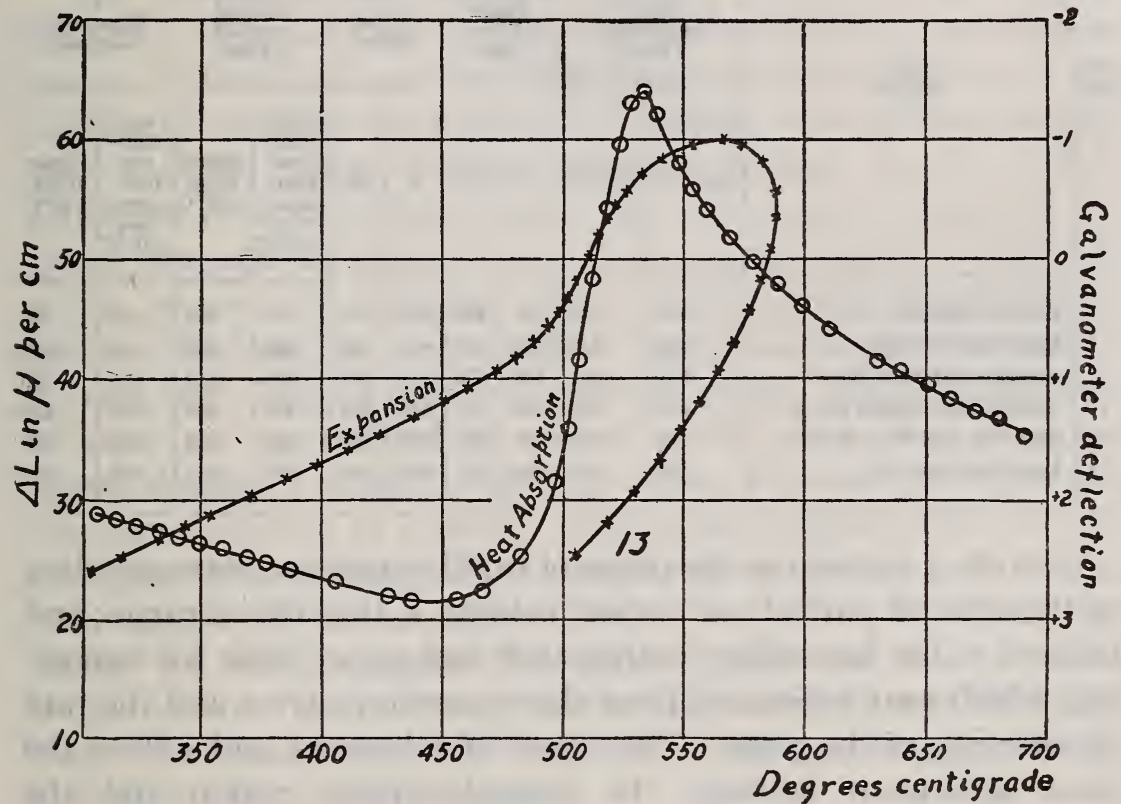

FIG. 21.-Thermal dilatation and heat absorption of light fint glass, B. S. I88 (specimen I3)

From these considerations its seems that most of the strain introduced depends upon the magnitude of difference in the expansion coefficients above and below the critical region, and the rate of cooling. Samples $I I$ and 22, for which the differential expansion is large, require much more careful cooling than Nos. I4 or 23 , for which it is small. For real thorough annealing the glass should be held for a long time at a temperature near the middle of the critical region. For more rapid annealing the sample can be held above the critical region, then cooled very slowly through that region and more rapidly the remainder of the way. 
The annealing and critical ranges of several optical glasses, as determined by Tool and Valasek, are compared in Table 5 with those obtained from our expansion measurements. The upper and lower limits of the heat-absorption ranges are given in column $3, \mathrm{~A}$ and $\mathrm{B}$, and the annealing temperature and the upper limit for annealing - that is, the highest temperature to which the glass can be heated without noticeable deformation - in column 6 .

TABLE 5.-Annealing and Critical Ranges of Several Optical Glasses

\begin{tabular}{|c|c|c|c|c|c|c|c|c|c|c|c|}
\hline \multirow{3}{*}{$\begin{array}{l}(1) \\
\text { No. }\end{array}$} & \multirow{3}{*}{$\stackrel{(2)}{\text { Iame }}$} & \multicolumn{6}{|c|}{ Critical range of heating } & \multicolumn{4}{|c|}{ Annealing range } \\
\hline & & \multicolumn{2}{|c|}{$\begin{array}{c}\text { Heat } \\
\text { absorption } \\
\text { (T001) }\end{array}$} & \multicolumn{2}{|c|}{$\begin{array}{c}\text { Rapid } \\
\text { expan- } \\
\text { sion }\end{array}$} & \multicolumn{2}{|c|}{$\begin{array}{l}(5) \\
\text { Critical } \\
\text { region }\end{array}$} & \multicolumn{2}{|c|}{$\begin{array}{l}\text { (6) } \\
\text { Optical } \\
\text { method } \\
\text { (Tool) }\end{array}$} & \multicolumn{2}{|c|}{$\underset{\substack{\text { Expansion } \\
\text { method }}}{(7)}$} \\
\hline & & $\mathrm{A} \pm 10^{\circ} \mathrm{C}$ & $\mathrm{B} \pm 5^{\circ} \mathrm{C}$ & $\mathbf{A}$ & B & $\mathbf{A}$ & $\mathbf{B}$ & $\begin{array}{l}\text { An- } \\
\text { neal- } \\
\text { ing } \\
\text { tem- } \\
\text { pera- } \\
\text { ture } \\
\pm 15^{\circ} \mathrm{C}\end{array}$ & $\begin{array}{l}\text { Upper } \\
\text { limit } \\
\pm 15^{\circ} \mathrm{C}\end{array}$ & $\begin{array}{l}\text { An- } \\
\text { neal- } \\
\text { ing } \\
\text { tem- } \\
\text { pera- } \\
\text { ture } \\
\pm 10^{\circ} \mathrm{C}\end{array}$ & $\begin{array}{l}\text { Upper } \\
\text { limit } \\
\pm 10^{\circ} \mathrm{C}\end{array}$ \\
\hline 1 & Barium flint No. $145 \ldots .$. & 520 & 560 & 520 & 570 & 500 & 525 & 515 & 550 & 510 & 580 \\
\hline 9 & Light crown No. $20 \ldots . .$. & 495 & 525 & 500 & 525 & 460 & 500 & 480 & 530 & 480 & 530 \\
\hline 10 & Borocilicate crown No. $94 \ldots .$. & 515 & 565 & 535 & 570 & 515 & 535 & 525 & 550 & 525 & 590 \\
\hline 11 & Light barium crown No. $87 \ldots$ & 575 & 605 & 585 & 610 & 545 & 585 & 570 & 610 & 565 & 620 \\
\hline 12 & Medium flint No. $110 \ldots . .$. & 455 & 485 & 450 & 680 & 430 & 450 & 460 & 510 & 440 & 500 \\
\hline 13 & Light flint No. $188 \ldots . . . \ldots \ldots$. & 485 & 525 & 490 & 525 & 460 & 490 & 485 & 510 & 475 & 540 \\
\hline
\end{tabular}

Column 4 represents the range of rapid expansion corresponding to the straight part of our curves; column 5 , the critical range; and column 7 , the annealing temperature and upper limit for annealing, which were estimated from the expansion curves and the rate of softening of the glass. The values of columns 3 and 4 show the close agreement between the heat-absorption region and the range of rapid expansion. The annealing temperature of column 7 , which is the mean of the critical region (column 5), agrees very well with the annealing temperature obtained by Tool and Valasek by the crossed nicol method. Their values for the upper limit are about the same as we obtain from the softening curves. Both methods, therefore, give the location of the annealing temperature and upper limit for annealing. The expansion measurements give also the coefficients of expansion, above and below the critical region, which make it possible to estimate the thermal resistance of the glass and the magnitude of the strains that a given annealing process will produce. 


\section{SUMMARY}

A review of the previous researches on the thermal expansion of glass shows that most of the determinations were confined to the temperature region below $100^{\circ} \mathrm{C}$, except in a few cases where glasses of unknown composition were taken to $500^{\circ} \mathrm{C}$. In this investigation, 'indertaken in connection with Bureau of Standards' production of optical glass, the dimensional changes of various glasses in the annealing and higher temperature region were determined. Upon requests from several glass manufacturers a number of their commercial products were also investigated.

The Fizeau-Pulfrich interferometer is particularly well adapted for this work, since the extreme sensitiveness of the interferometer makes it possible to use small specimens, and the small size of the apparatus simplifies the problems of uniform heating and temperature control. Using straight fringes produced by the yellow radiation from a helium source, the dimensional change for a given temperature interval was given by the number of fringes which passed the reference mark on the front interferometer plate. Observations were made in temperature regions between 20 and $650^{\circ} \mathrm{C}$ on 32 different kinds of glass. Their dimensional changes are represented by curves which show that the glass passes through a critical expansion region, in which the expansion rate increases by 2 to 7 times. This critical region, which for any one glass does not exceed $40^{\circ}$, was found as low as $400^{\circ} \mathrm{C}$ with Nos. 24 and 30 , and as high as $575^{\circ} \mathrm{C}$ with No. II. About $75^{\circ}$ above the critical region the glass softens and contracts. A comparison of results show that the heat absorption observed by Tool and Valasek occurs in the same temperature region as the critical change in the expansion.

From these determinations of the dimensional changes of glass the following information is obtained: The thermal expansion above and below the critical temperature, the temperature for most careful and thorough annealing, the upper limit for rapid annealing, and the region where careful cooling is essential.

Washington, April I4, I920. 


